\title{
La porcelana de sepiolita de Bartolomé Sureda (1802-1808). Investigación arqueométrica sobre la Real Fábrica de Buen Retiro.
}

\author{
C. PASCUAL ${ }^{A}$, E. CRIADO ${ }^{A}$, P. RECIO ${ }^{A}$, R. MARTINEZ ${ }^{A}$, A. H. DE AZA ${ }^{A}$, F. J. VALlE ${ }^{A}$, C. MAÑUECO ${ }^{B}$. \\ a Instituto de Cerámica y Vidrio, CSIC, Kelsen 5, 28049 Madrid. \\ b Museo Arqueológico Nacional. Serrano 13, 28001 Madrid.
}

\begin{abstract}
Este trabajo considera el estudio arqueométrico de un tipo de porcelana muy poco frecuente que se elaboró en los últimos años de la Real Fábrica de Porcelanas del Buen Retiro (1803-1808) bajo la dirección de Bartolomé Sureda. El análisis químico y mineralógico de una selección de fragmentos de vajillas, azulejos y esculturas, que se encontraron en la excavación arqueológica (1996) del solar de la fábrica, ratifica la producción de un nuevo tipo de porcelana dura, en la que se empleaba una arcilla de magnesio, la sepiolita, en lugar del caolín. Las características de las pastas y los vidriados y la investigación del contexto histórico y científico de la porcelana y la cerámica blanca en Europa han permitido establecer los motivos y los parámetros de su producción. La reproducción de la pasta a escala de laboratorio confirma las materias primas utilizadas y el tratamiento térmico empleado.
\end{abstract}

Palabras clave: Keywords: SEM-EDS, Arqueometría, Porcelana, Diagramas de fase, Buen Retiro, Sureda, Siglo XIX.

Bartolomé Sureda's sepiolitic porcelain (1803-1808). Archaeometric study of the Buen Retiro Royal Porcelain Manufacture.

This work deals with an original class of porcelain produced under the direction of Bartolomé Sureda in the last years (18031808) of the Royal Porcelain Factory of Buen Retiro. The results of the chemical and mineralogical analysis of a selection of tableware, tiles and sculpture shards, found in the archaeological excavation (1996) of the site where the factory was built, confirm the production of a new hard-paste porcelain where the kaolin was substituted by a magnesium clay, the sepiolite. The characteristics of pastes and glazes and the investigation of the historic and scientific contexts of porcelain and white earthenware in Europe have allowed establishing the reasons and the technical parameters of this production. Replicas of the paste were done in the laboratory to assert the raw materials and the firing conditions of this porcelain.

Keywords: Archaeometry, SEM-EDS, Porcelain, Phase diagrams, Buen Retiro, Sureda, 19th Century.

\section{INTRODUCCIÓN}

Este trabajo ha continuado la investigación iniciada en los dos proyectos dirigidos por Salvador de Aza sobre la Fábrica de Porcelana del Buen Retiro, ${ }^{1,3}$. Además de la porcelana de Sureda, en la que se centraron estas memorias, el estudio de los restos de porcelana encontrados en el Huerto del Frances, así como el de otras muestras procedentes de la restauración de piezas bien catalogadas y recientemente de muestras procedentes de los gabinetes de porcelana de los Reales Sitios, han sido tarea de otros proyectos ${ }^{4,5}$ en los que Salvador de Aza continuó participando con el mismo entusiasmo con que comenzó la andadura de la Porcelana de Buen Retiro.

La Arqueometría, tal como la entendió también Salvador de Aza, es una tarea multidisciplinar en la que tenían que confluir y entenderse "las dos Culturas" y por eso este trabajo ha tenido como objetivo la recuperación de la última etapa (1803-1808) que dirigió Sureda a través de sus documentos históricos, los textos científicos de la época y el estudio de la porcelana que se hizo entonces, con los criterios y los medios que se emplean hoy en la investigación y el desarrollo de los materiales cerámicos.
Bartolomé Sureda y la Manufactura del Buen Retiro (1803-1808).

En la historia de la porcelana española, el nombre de Bartolomé Sureda permanecerá siempre unido a la etapa final de la Manufactura del Buen Retiro, la empresa que había fundado Carlos III (1759-1788) y que, por imperativos del destino, sólo estuvo en funcionamiento medio siglo (17601808). La incorporación de Sureda a la fábrica madrileña inauguró un periodo de cambios, que afectaron a toda la estructura de toda la empresa.

Bartolomé Sureda y Miserol (1769-1850) había nacido en Palma de Mallorca. Desarrolló su primer trabajo colaborando con Agustín de Betancourt en el Gabinete de Máquinas, manifestando siempre una fuerte inclinación por el mundo industrial. La experiencia lograda en el sector textil durante su estancia en Inglaterra -que aplicaría más tarde en las Reales Fábricas de Hilados de Lana de Guadalajara-, al igual que los conocimientos adquiridos en París le fueron dotando de una formación muy sólida, que le permitió desarrollar una gestión eficaz e impecable al frente de la Manufactura de Buen Retiro y dirigir, igualmente, la Fábrica de Loza de La Moncloa y la Real Fábrica de Cristales de La Granja. Cultivó el dibujo y 
desempeñó un papel importante en la historia de la litografía en España. Jubilado en 1829, se retiró a su ciudad natal, donde permaneció hasta el final de su vida ${ }^{6}$.

El cambio de siglo había coincidido con una situación complicada en la fábrica madrileña, provocada por conflictos de índole muy diversa; por una parte, los costos de mantenimiento se habían disparado, pues, a la carestía de la vida, había que añadir una larga nómina de empleados, secundada por las cada vez más numerosas pensiones y ayudas a viudas y huérfanos, quiénes, además, disfrutaban todavía de viviendas dentro en la fábrica, impidiendo que fueran ocupadas por operarios en activo; por otra, los sueldos no se pagaban regularmente, el Intendente carecía de autoridad moral y la disciplina se había relajado. Agravaban la situación los problemas internos que arrastraba el Obrador de fabricación de Pasta, incapaz de obtener después de tanto tiempo, por uno u otro motivo, porcelana de pasta dura, algo que venía reclamando Carlos IV (1788-1808) desde su ascenso al trono.

En enero de 1802, el monarca, cansado ya de tanta espera y deseoso de lograr en Madrid "la misma perfección técnica conseguida en París" ${ }^{\prime 7}$ comienza a actuar por su cuenta y ordena al Cónsul de España en París contactar "con la más escrupulosa reserva" con Bartolomé Sureda, que residía temporalmente en esa capital, a fin de que, con su ayuda, se trajeran a España los conocimientos en el ramo de la porcelana ${ }^{8}$. Un mes más tarde hace llegar a Sureda muestras de las tierras y barnices utilizados en Buen Retiro, con la intención de que pudieran ser comparados con los que se empleaban en Sèvres; poco tiempo después, solicita a la manufactura francesa el envío a Madrid de unas muestras, con el fin de llevar a cabo en España una búsqueda paralela9. Deseoso de ganar tiempo, en el mes de mayo encomienda a Sureda "instruirse en la mas exquisita china en Sèvres", junto a Alexandre Brongniart, un reputado ingeniero de minas que permaneció al frente de esa manufactura francesa durante medio siglo. En el mes de junio, quizá a consecuencia de haber recibido las muestras francesas en Madrid, se da la orden de recorrer parajes diversos para seguir recogiendo nuevos materiales ${ }^{10}$. Con este proceder tan enérgico, el rey demostraba que estaba decidido a cambiar el rumbo de la manufactura madrileña.

En octubre de 1803, Sureda regresó a Madrid para hacerse cargo de Buen Retiro. Los pasos que hubo de dar hasta poder fabricar porcelana de pasta dura, los cuenta él mismo en un interesante informe que redactó en noviembre de 1808, cuando estaba a punto de abandonar definitivamente Buen Retiro; el texto completo, localizado en un archivo madrileño, nos permitió en su día profundizar en el conocimiento de la manufactura madrileña y publicar nuevos datos sobre este periodo ${ }^{11}$.

Cuenta en el informe que "... el primer cuidado fue el examen de la porcelana que se trabajaba en la fábrica en la que encontré que era igual en calidad y elaboración a la que se abandonó en Francia el año 1760 ... porque se ignoraban los descubrimientos que se habian hecho en Francia treinta años antes ... y ni tenían ni habian buscado materiales a propósito, ni conocían el mecanismo de la fabricación". Una afirmación tan exacta ya presagiaba que tendría que recorrer todavía un largo camino, hasta poder obtener porcelana de buena calidad. Es cierto que en lo tocante a los materiales empleados para producir la nueva porcelana, podía disponer de feldespato, que se había descubierto en España poco antes de su llegada, pero también es verdad que le faltaba lo más importante, las tierras arcillosas. El nuevo director estuvo practicando durante siete largos meses toda clase de ensayos con las tierras que tuvo a su alcance y cuando prácticamente había perdido la esperanza de fabricar porcelana, empezó “... a obtener algún resultado lisongero con la tierra que se encuentra entre Vicálvaro y Vallecas". En junio de 1804 Sureda presentó al rey las primeras piezas realizadas con los nuevos materiales, con el orgullo de "ser el primero que había hecho verdadera porcelana en España". El resultado obtenido constataba que estaba en el buen camino, pero era sólo un ensayo, susceptible de ser mejorado, y no impidió que en los dos años siguientes, se siguieran buscando y se localizaran nuevos yacimientos en los alrededores de Madrid ${ }^{12}$.

Las primeras piezas se habían obtenido utilizando unas instalaciones anticuadas, de las que formaban parte un molino de molienda y un horno inservibles, dos instrumentos fundamentales a la hora de producir porcelana. Llegado a este punto, Sureda comprendió que había llegado el momento de, por una parte, modernizar los talleres y, por otra, completar el ordenamiento jurídico de la fábrica para, entre otros fines, agilizar el funcionamiento de la misma. Y abordó este nuevo reto confeccionando una Reglamento, de cuya existencia, no del contenido, dio razón en su día Pérez Villamil ${ }^{13}$. El documento lo encontramos hace años en un archivo madrileño ${ }^{14}$; el texto rompía con todo lo anterior, pues a lo largo del articulado se descentralizaban las funciones, se imponía un mayor control y se inauguraba una dirección colegiada, con la participación de todos los cargos de responsabilidad de la fábrica. Hasta este momento, la manufactura había estado a cargo de un Intendente que centralizaba en su persona la dirección y gestión de personal, los temas económicos, trámites administrativos y la supervisión y conservación del edificio. Por si esto fuera poco, era también el responsable último de la producción, si bien no intervenía directamente en el trabajo técnico y artístico de los Obradores. La experiencia de los últimos años había demostrado lo poco operativo del sistema y lo peligroso que podía resultar concentrar tanto poder en la misma persona. Quizá por eso el nuevo texto desgajaba de la Intendencia el sector económico administrativo, haciéndolo depender de un Contador quien, además, tenía a su cargo el control de las piezas fabricadas, así como los Libros de Juntas y la obligación de redactar anualmente un inventario de los materiales existentes y de las piezas vendidas o entregadas al Real Servicio. Para velar por los caudales se procuró un arca con tres llaves que custodiarían el Intendente, el Contador y el Guarda-Almacén; los tres deberían presenciar su apertura una vez por semana. En el sector técnico y artístico los directores de los Obradores y Escultura y de Pintura pasaron a depender de un Director General de Labores, que se ocupaba igualmente de la selección de personal y de la conducta de los operarios.

En Septiembre de 1804 Sureda sometió el texto a la aprobación del monarca, quién aprobó el Reglamento y autorizó las reformas de las instalaciones de la fábrica, que se prolongaron hasta el comienzo de 1806. Estas fechas evidencian que Buen Retiro sólo pudo fabricar porcelana de pasta dura a pleno rendimiento desde que finalizaron las reformas en 1806, hasta mayo de 1808, fecha en la que los franceses paralizaron la producción. Ahora bien, durante ese espacio de tiempo se siguieron buscando nuevos yacimientos y, al parecer, Sureda continuó perfeccionando la pasta, tal y como se desprende de su comentario, al afirmar "haber conseguido con una tierra de Galicia todo lo que se puede desear pero que había sido en la época cuando tuvimos que abandonar la fábrica por ocuparla las tropas francesas". 
Es un hecho admitido por todos que, desde un punto de vista industrial, la fabricación de la pasta con la "tierra de Vallecas" supuso la mayor aportación de Sureda a la porcelana española y, además, vino a coincidir con uno de los momentos más interesantes de la manufactura madrileña.

En otoño de 1804, coincidiendo con el inicio de las obras, el monarca encargó a Sureda la fabricación y colocación de un pavimento de porcelana, que iría destinado a unas estancias de la planta alta de la Casita del Labrador de Aranjuez. El encargo reportaba claras ventajas para el erario, pues no sólo evitaba el coste de un solado lujoso, sino que, además, permitía obtener un rendimiento a la inversión realizada en Buen Retiro. Sin embargo, el director de la manufactura lo veía de otro modo; por una parte consideraba que su ejecución era difícil y que sólo podía desarrollarse con éxito en una fábrica experimentada en el empleo de la porcelana dura; por otra, estaba seguro de que este encargo retardaría notablemente el resto de la producción, algo que le contrariaba notablemente. No obstante, Sureda logró fabricar poco más de ocho mil baldosas, cuya cocción le produjo serios quebraderos de cabeza especialmente en los primeros tiempos, no sólo por las condiciones del horno, sino también por el propio combustible, pues él reclamaba con insistencia partidas de fresno y álamo blanco por su mayor poder calorífico, solicitando además una leña con cierto grado de secado y con un corte de determinado tamaño, algo que no se contemplaba en las Ordenanzas de la Corte ${ }^{15}$. Todos los azulejos que se han conservado fueron decorados de forma sencilla, con motivos vegetales $\mathrm{y} / \mathrm{o}$ geométricos. La paleta ofrece colores muy variados, pero logra mayor calidad en las tonalidades más claras.

Sureda compaginó la ejecución del pavimento con dos clases de obras: cierto número de figuras de carácter alegórico o mitológico y algunos objetos destinados para el servicio de la mesa, principalmente piezas de servir y juegos de té y café, que llevaron a cabo escultores, pintores, modeladores y adornistas de primera línea. En estos años, además de las figuras mencionadas, el Obrador de Escultura hizo frente a otro encargo para la Real Casa, un gran centro de mesa dedicado a las Letras y las Artes Españolas, que estaba presidido por Apolo y las Musas, los moradores del Parnaso. Era éste un proyecto muy ambicioso que, desgraciadamente, quedó inacabado. Las figuras que se han conservado responden a un canon neoclásico, presentan un modelado muy correcto y están acabadas en blanco, la mayor parte de las veces en bizcocho.

Conseguir que Buen Retiro dejara de ser una carga para el Tesoro, formaba parte de los planteamientos de Sureda y, de acuerdo con esta premisa, se decidió por fabricar piezas de vajilla que tuvieran una fácil salida en el mercado. Posiblemente con este fin, se inclinó por seleccionar tipologías atractivas, un repertorio decorativo variado - paisajes, escenas en reserva, bustos de perfil, motivos tomados del mundo antiguo, etc., siempre contemplados desde una óptica nueva, y una paleta alegre, cuyas tonalidades amarillas, verdes, salmón o fucsia resultaban totalmente innovadoras. No satisfecho con estos logros, incorporó también los fondos de color, que tantos problemas habían causado al Obrador de Pintura en la época anterior. Finalmente, tras la creación de un Obrador de Dorado, enriqueció las piezas con orlas y detalles dorados de excepcional calidad ${ }^{16}$.

Si las obras fabricadas en estos años evidencian una ruptura con todo lo anterior, Sureda aplicó el mismo criterio a la hora de elegir las marcas de la fábrica para identificar la producción de Buen Retiro bajo su mandato. Reemplazó la tradicional flor de lis por un sello circular impreso, con los caracteres R/MADRID/S (Retiro/Madrid/Sureda) orientados verticalmente, que aparece en la obra escultórica, cuando la pieza aparece marcada, y por las letras Md (Madrid) bajo corona, pintadas sobre cubierta en rojo, azul o dorado, para los objetos de vajilla (Figura 1).

\section{El contexto científico y técnico de la porcelana de Sureda.}

La porcelana que fabricó Sureda supuso una innovación, al emplear la "tierra de Vallecas", una piedra silícico-magnésica distinta del caolín, que tuvo gran repercusión al menos en el ámbito científico. En una carta dirigida a Vauquelin, cuyo resumen se publicó en los Annales des Arts et Manufactures ${ }^{17}$, Proust aseguraba que era superior a la de Sèvres. Esta porcelana fue novedosa pero no fue una "invención inesperada", como lo califica Pérez-Villamil ${ }^{18}$, lo mismo que no había sido casual ni el descubrimiento de la porcelana en Meissen en $1709^{19} \mathrm{ni}$ el desarrollo de la porcelana en Europa a lo largo del siglo XVIII.

La primera porcelana europea que se conoce es la fabricada en Florencia entre 1564 y 1578 bajo el patronazgo de Francisco I de Medici ${ }^{20}$. Después de este breve periodo la producción parece cesar en Europa hasta que en 1695 en St. Cloud (Francia) se comienza a elaborar, tras casi veinticinco años de ensayos, una porcelana tierna, también conocida como porcelana artificial, formulada como la de Medici a partir de una frita, pero a la que se añadía cal y una marga calcárea ${ }^{21,22}$. Esta fórmulación se extendió por toda Europa y fue la base de las porcelanas tiernas que se elaboraron hasta principios del siglo XIX. La porcelana tierna distaba mucho de la porcelana china que deseaba imitar; se cocía, dentro de unos márgenes muy pequeños, a baja temperatura $\left(1000-1100{ }^{\circ} \mathrm{C}\right)$, la cubierta se rayaba fácilmente y sobre todo tenía una resistencia al choque térmico muy baja.

La gloria del "descubrimiento" de la "verdadera porcelana" en Europa la tuvo Böttger, un alquimista alemán, en Meissen en 1709 y la Historia tendió a eclipsar el trabajo de Thchirnhaus, que con una sólida formación científica había estado investigando sobre la fabricación del vidrio y la porcelana desde veinte años antes ${ }^{23}$. En 1706 Böttger comenzó a trabajar con Thchirnhaus, que muere meses antes de que Böttger presente al rey la primera porcelana a partir de la mezcla de dos arcillas, cuarzo y alabastro. El caolín alemán se descubrió hacia 1708 , pero la porcelana triaxial con el feldespato no se empezó a fabricar hasta 1720.
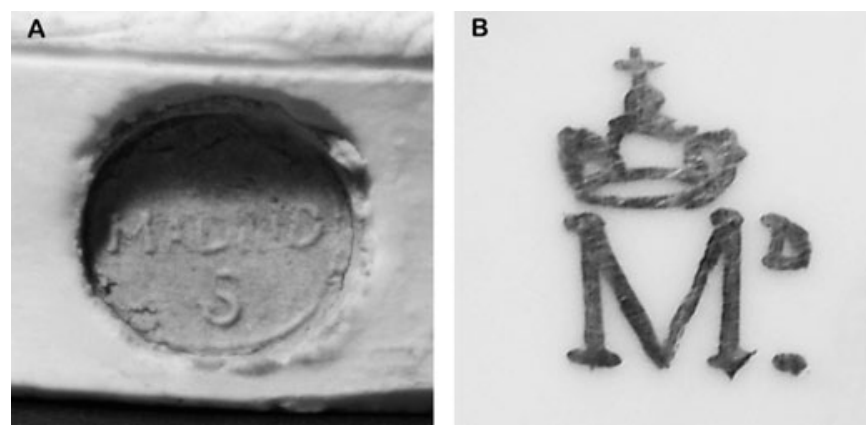

Figura 1. Marcas de Buen Retiro en el periodo de Bartolomé Sureda. 

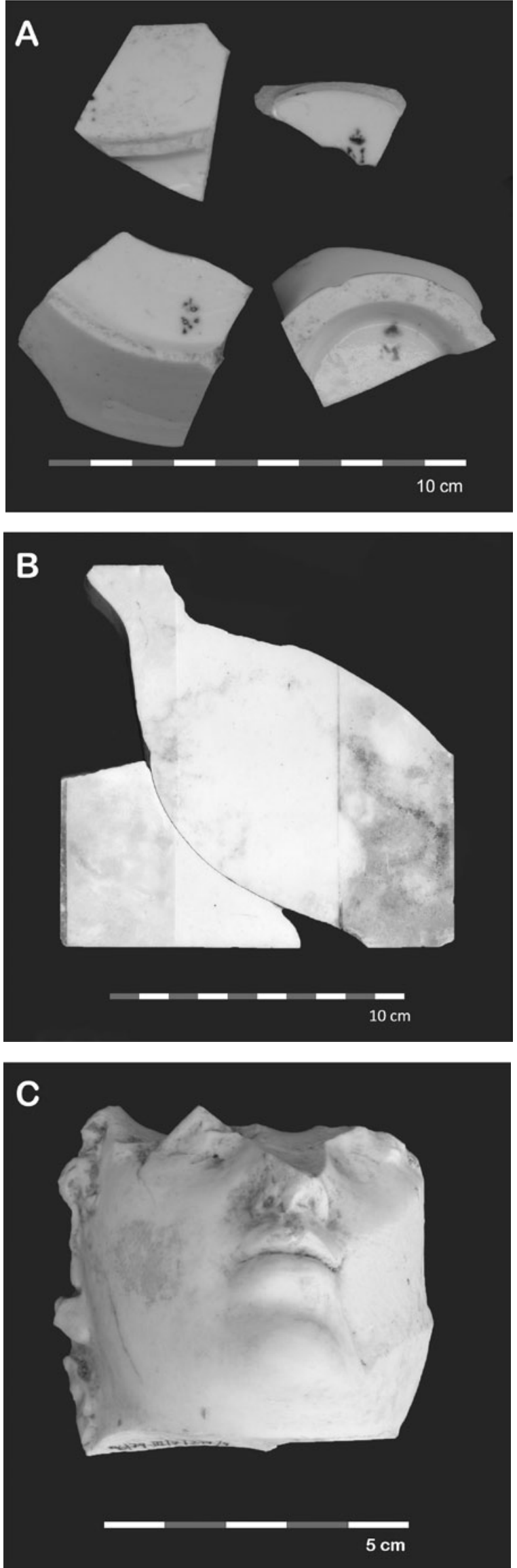

Figura 2. Muestras de los tres tipos de restos arqueológicos de porcelana; vajilla (A), baldosas (B) y escultura (C), que se encontraron en el Huerto del Francés ${ }^{38}$.
El secreto de la fabricación de la porcelana china fue desvelado, en parte, a través de las dos cartas, 1712 - 1722, del Pere D'Entrecolles procedentes de las Misiones Jesuitas en China ${ }^{24}$. En ellas, además de mandar algunas tierras, se informaba de los nombres, Petun-tsé, Kao-lín y Hoa-ché, y de la proporción de los componentes minerales de la porcelana, incluyendo una descripción detallada del procesamiento, de la cocción e, incluso, la formulación de los vidriados y de la decoración. A pesar de esta información y de la investigación de los más prestigiosos científicos como Reaumur ${ }^{25,26}$, la confusión sobre las materias primas y la dificultad de alcanzar la temperatura eran tales que la mayoría de las manufacturas fabricaban a mediados de siglo solo porcelana tierna.

El avance de la Mineralogía y la Química fue decisivo en el desarrollo de la porcelana especialmente en el último tercio del siglo XVIII. La llamada Revolución Química estableció las teorías de la constitución de la materia y las leyes de las afinidades, las relacionó con los métodos de análisis y la purificación de las sustancias y se involucró en la búsqueda de nuevas tierras y nuevas fórmulas para la porcelana. Entre los químicos destacaron Pott, que en su tratado "Lithogeognosie"27 clasificó las tierras en cuatro grupos e investigó caolines y feldespatos en la fábrica de porcelana de Berlín, y Macquer, que estableció la reactividad a alta temperatura de numerosísimas rocas y tierras y cuyas investigaciones culminaron con la fabricación de la porcelana dura en Sèvres, pero hubo más autores que, como Gettard, Morveau, Kirwan, Lavoisier, Proust y otros muchos, contribuyeron al desarrollo de las Ciencias Aplicadas a la minería y a las más diversas manufacturas. Entre los grandes tratados sobre la porcelana se encuentran el de Montamy ${ }^{28}$, el de Milly ${ }^{29}$ y el de la Enciclopedia ${ }^{30}$. Aunque Brongniart, director de Sèvres entre 1800 y 1847, escribió el Traité des Arts Céramiques ${ }^{31,32}$ cuarenta años más tarde, este tratado da una idea más precisa de los conocimientos que Sureda aplicó en el desarrollo de su porcelana.

De los 31 elementos químicos que se descubrieron en el siglo XVIII, tres (Pt, W y V) lo fueron hechos por españoles y sin embargo no queda apenas noticia del desarrollo de la Química y la Mineralogía en España, o al menos que esté reflejada en tratados científicos generales. El esfuerzo por difundir el conocimiento que se generaba en Europa quedó patente en la traducción de la mayoría de los autores citados e incluso en la edición de obras de divulgación como las "Memorias Instructivas y Curiosas ..." de Madrid, la "Gaceta de Literatura de México" o el "Mercurio Peruano" que tradujeron algunos de los textos más conocidos sobre Química, Metalurgia e incluso sobre la Porcelana. De ello puede deducirse que, al menos en sus aspectos teóricos, Buen Retiro, que desde su fundación en 1760 elaboraba porcelana tierna con el más alto nivel artístico, disponía de una base científica sobre la cual podía fabricar la tan ansiada "verdadera porcelana". Tan solo era necesario encontrar yacimientos de suficiente calidad de caolín y de feldespato.

La escasa actividad científica del país se intentó paliar trayendo químicos y mineralogistas extranjeros, como Proust que comenzó a trabajar en Vergara hacia 1780 y Herrgen que fue contratado como colector de minerales hacia 1790 y llegó a dirigir el Real Gabinete de Historia Natural de Madrid. Aunque vinieron más y su trabajo fue considerable en la búsqueda de nuevos minerales ${ }^{33}$ nunca llegaron a cubrir la inmensa demanda de investigación de la minería de España y de sus entonces colonias en América ${ }^{34}$. En ningún texto 
se menciona a Buen Retiro, seguramente porque no llegó a encontrarse el caolín y los gastos que había tenido la Fábrica, trayendo materias primas, eran escandalosos ${ }^{35}$, más, si se considera que prácticamente toda su producción estaba destinada exclusivamente al uso del rey ${ }^{36}$.

El desarrollo de la porcelana de Sureda debió contar, además de con una base científica, con una serie de conocimientos técnicos más difíciles de encontrar en los textos. En el caso de Sureda se conserva su "Cuaderno de Notas sobre Cerámica (1802$1826)^{\prime \prime 37}$ que recoge, sin ser muy sistemático, los apuntes que fue tomando durante su aprendizaje en París y algunas notas de su trabajo en Buen Retiro y Moncloa.

\section{EXPERIMENTAL}

\section{Selección de las muestras.}

Las muestras se seleccionaron entre los restos de cerámica encontrados en la excavación del Huerto del Francés intentando cubrir los tres posibles tipos de producción, vajilla, escultura y baldosas, que realizó la Real Fábrica de Porcelana del Buen Retiro bajo la dirección de Bartolomé Sureda. La mayoría de los restos de porcelana, la prospección arqueológica recuperó más de 800 fragmentos de cerámica, se encontraban en una misma unidad estratigráfica (UE - 219) que se formó por la descarga de materiales de demolición de la Fábrica en el hueco de una alberca ya parcialmente relleno $^{38}$. No se trata del foso, lógicamente estratificado, de los desechos de las sucesivas etapas productivas y las muestras, generalmente fragmentos muy pequeños de los que difícilmente se pueden establecer paralelos con elementos catalogados, responden indiscriminadamente a cualquier época de la Fábrica.

A partir de las primeras tres piezas de vajilla que se estudiaron en el Primer Proyecto (1999-2001) ${ }^{39}$ que estaban marcadas con la M coronada (Figura 2A) característica de la última etapa de Buen Retiro, la serie de muestras de vajilla se aumentó con los únicos fragmentos que habían aparecido con esta marca (Figura 2A) en los restos disponibles de la excavación y algunos fragmentos de asas, tapaderas, bordes de platos etc., que podían aproximarse con mayor o menor acierto a piezas conocidas de las colecciones de Buen Retiro. Por último se consideraron dos pequeñísimos fragmentos, menores de $0.5 \mathrm{~g}$, procedentes de la restauración de dos piezas de vajilla, perfectamente conocidas y catalogadas, procedentes de colecciones privadas.

En el Segundo Proyecto ${ }^{40}$ se pudo establecer la similitud de algunos restos de baldosas encontrados en el Huerto del Francés (Parque del Retiro) con las de los dos pavimentos de porcelana que aún se conservan en la Casita del Labrador de Aranjuez. De acuerdo con la documentación que Carmen Mañueco aportó en los dos proyectos que dirigió Salvador de Aza, además de estos dos suelos que comenzaron a colocarse en 1806, Bartolomé Sureda preparo una tercera partida de baldosas en los primeros meses de $1808^{41}$ que hasta el momento no ha sido localizadas. En este trabajo se han incluido un grupo de baldosas cuya decoración en blanco, lila y amarillo pálido difería claramente de los pavimentos aún conservados en Aranjuez (Figura 2B).

Los restos de escultura, encontrados en dos unidades estratigráficas (UE - 219 y UE - 226), corresponden al menos a tres figuras de distinto tamaño, seguramente retratos, de los que se han encontrado fragmentos de las cabezas (Figura 2C) y distintas condecoraciones y partes de uniformes de marina.

El estudio de las materias primas se ha centrado en la caracterización química y mineralógica de dos arcillas de magnesio que pueden corresponder a la denominación "Vallecas" en los documentos de Bartolomé Sureda. Así se han analizado dos arcillas del entorno Vicávaro-Vallecas, la "Arcilla Sepiolitica" y la "Bentonita Magnésica", que la empresa Tolsa SA explota en la actualidad en los yacimientos del Cerro Almodovar. Las muestras se recogieron en las zonas que podrían estar en explotación a principios del Siglo XIX, en la época en que Bartolomé Sureda dirigió la Fábrica de El Buen Retiro.

\section{Caracterización de los restos de porcelana}

La caracterización mineralógica de las fases cristalinas que constituyen las porcelanas se realizó en las muestras molidas, una vez eliminado el vidriado, mediante difracción de rayos X (XRD) en un equipo Siemens - D 5000 utilizando la radiación $\mathrm{K} \alpha$ del $\mathrm{Cu}$. Los difractogramas se tomaron entre $2^{\circ}$ y $70^{\circ}(2 \theta)$ con un paso de $0.05^{\circ}(2 \theta)$ y adquisición de 1.5 segundos por paso. En la identificación de los pigmentos la exploración se realizó sobre la superficie coloreada de las baldosas utilizando el dispositivo de ángulo rasante (ángulo de incidencia de $4^{\circ}$ ) del mismo equipo con un paso de 0.1

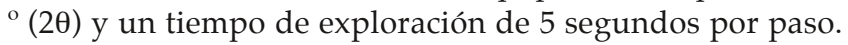

La composición química de la porcelana y el vidriados se determinó, cuando el tamaño de la muestra lo permitía, mediante fluorescencia de rayos X (XRF) en un espectrómetro Philips, MagiX SuperQ provisto de un generador de rayos $\mathrm{X}$ de $\mathrm{Rh}(2.4 \mathrm{~kW})$ en perlas de fusión alcalina de $0.3 \mathrm{~g}$ de muestra en $\mathrm{LiBO}_{4}$. En el caso de muestras muy pequeñas el análisis se realizó solamente mediante microanálisis EDS. El análisis se redujo a los componentes mayoritarios por tratarse, al contrario de los productos de barro cocido, de materiales en los que entran en su formulación cantidades variables de distintas materias primas.

Para el análisis microestructural las muestras se cortaron perpendicularmente a la superficie vidriada, se embutieron en resina epoxi y se pulieron progresivamente con papel de $\mathrm{SiC}$ y pasta de diamante hasta $3 \mu \mathrm{m}$. La mitad de la superficie pulida de cada muestra se trató con una disolución acuosa de ácido HF al $10 \%$ en volumen durante periodos sucesivos de 30 segundos hasta que se comprobó el adecuado contraste de las fases en un microscopio óptico de luz reflejada C. Zeiss, provisto de procesadores de imágenes Axiophot y HP1.

Las microestructuras de la base de porcelana y la capa de vidriado, cuando lo había, se estudiaron examinando el área atacada en un microscopio electrónico de barrido de emisión de campo (FE-SEM) Hitachi-S4700 provisto de detectores de electrones secundarios y retrodispersados. La composición elemental se determinó con un espectrómetro de energías dispersivas de rayos $\mathrm{X}$, Noran (EDS-WDS), acoplado al FE-SEM que operaba a $20 \mathrm{kV}$ y $10 \mathrm{~mA}$. Las composiciones globales de la porcelana y el vidriado se determinaron con esta técnica promediando el análisis de al menos seis áreas, de aproximadamente $400 \times 300 \mu \mathrm{m}$ en la base y de $30-150 \mathrm{x}$ $300 \mu \mathrm{m}$ en la cubierta, de la zona no atacada de las muestras. 


\section{Caracterización de las materias primas.}

Además de la caracterización química mediante fluorescencia de rayos $\mathrm{X}$, mineralógica mediante difracción de rayos $\mathrm{X}$ y microestructural mediante microscopía electrónica de barrido de emisión de campo, realizadas en las condiciones descritas, las materias primas fueron específicamente estudiadas con otras técnicas.

Para la observación morfológica, la medida del tamaño de partícula y el estado de agregación de los polvos de las materias primas se utilizó un microscopio electrónico de transmisión Hitachi H-7100 (125Kv) equipado con un sistema de microanálisis EDS Rontec.

El equipo Netzsch STA409/C, que incorpora un controlador de temperatura Netzsch TASC 414/2, fue utilizado para el registro simultaneo de los efectos endo-exotérmicos sufridos por el material durante el tratamiento térmico y la pérdida o ganancia de peso asociada a los mismos. Como material de referencia se utilizó $\alpha$-alúmina calcinada. La velocidad de calentamiento fue $5{ }^{\circ} \mathrm{C} / \mathrm{min}$ y la temperatura máxima alcanzada $1350{ }^{\circ} \mathrm{C}$.

El estudio de las variaciones dimensionales, contracción - dilatación, con la temperatura se realizó en un Dilatómetro horizontal Adamel Lhomargy DI-24, con soporte de alumina. Los ensayos se realizaron entre temperatura ambiente y 1300 ${ }^{\circ} \mathrm{C}$, siendo la velocidad de calentamiento y enfriamiento $5{ }^{\mathrm{a}} \mathrm{C} /$ min. Para el estudio se prepararon probetas cilíndricas de 15 $\mathrm{mm}$ de longitud conformadas por prensado uniaxial.

La medida de la superficie específica del material en polvo se llevó a cabo por adsorción de nitrogeno a $77 \mathrm{~K}$ por el método BET de un punto, en un equipo Monosorb Surface Area Analyser MS-13 de Quntachrome.

\section{Reproducción de la porcelana}

La caracterización elemental y mineralógica de las materias primas se complementó con el estudio de la sinterización de una composición preparada a partir de la "Arcilla Sepiolítica" comercializada y de feldespato y cuarzo similares en el grado de molienda y pureza a los que se emplean en la industria cerámica. Los ensayos de sinterización dinámica se realizaron en el dilatómetro ya descrito. Para los de sinterización estática se prepararon probetas cilíndricas (10 $\mathrm{mm}$ de diámetro y 4 $\mathrm{mm}$ de altura) por prensado uniaxial que fueron sometidas

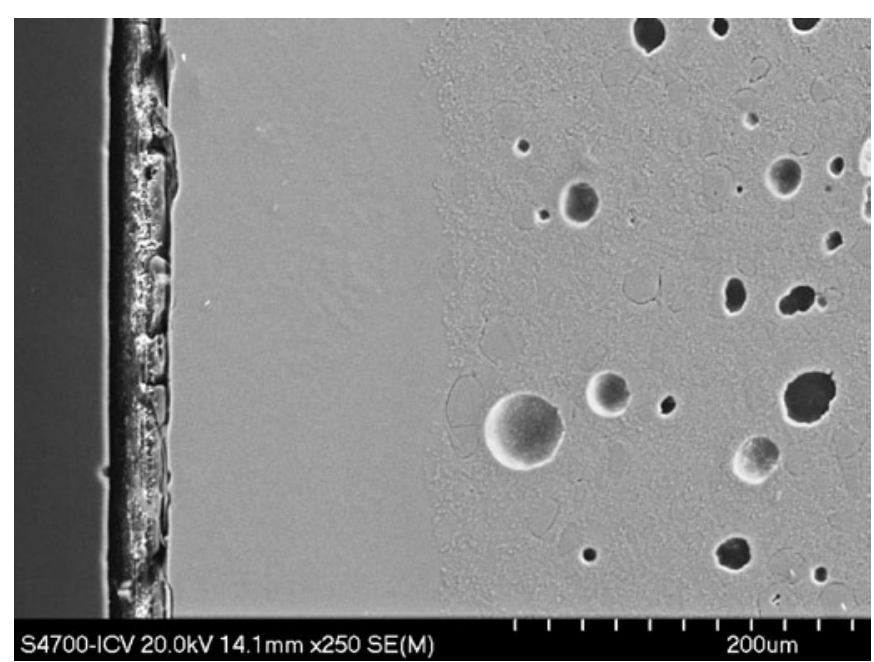

Figura 3. Microfotografía (FE-SEM) de la sección perpendicular a la superficie de una baldosa en la que se distinguen, de derecha a izquierda, la base de porcelana, el vidriado y la fina capa de color.

a tratamientos de 2, 24 y 48 horas entre 900 y $1300{ }^{\circ} \mathrm{C}$ en un horno de cámara Carbolite, con resistencias de super Kantal. Las porcelanas resultantes fueron estudiadas mediante XRD y SEM.

\section{RESULTADOS}

En la Figura 3 se presenta la microfotografía de la sección perpendicular a la superficie de una muestra tomada de una baldosa en la que se pueden apreciar las tres partes fundamentales: la base de porcelana, en la que se distinguen inmersos en la fase vítrea los granos de cuarzo rodeados por grietas circulares y los pequeños aglomerados de silicato de magnesio; la cubierta o vidriado, cuyo espesor oscila entre 100 y $150 \mu \mathrm{m}$; y la capa coloreada con un espesor entre 5 y $20 \mu \mathrm{m}$. En la Figura 4 se observa con más detalle la capa coloreada, a la izquierda, adherida al vidriado, a la derecha. El esmalte consiste en aglomerados de pequeños cristales del pigmento dispersos en una matriz vítrea.

TABLA 1. COMPOSICIÓN PROMEDIO Y DESVIACIÓN ESTÁNDAR DE LA PORCELANA EN LOS DISTINTOS TIPOS DE MUESTRAS ESTUDIADOS.

\begin{tabular}{|c|c|c|c|c|c|c|c|c|c|}
\hline & $\mathrm{Na}_{2} \mathrm{O}$ & $\mathrm{MgO}$ & $\mathrm{Al}_{2} \mathrm{O}_{3}$ & $\mathrm{SiO}_{2}$ & $\mathrm{P}_{2} \mathrm{O}_{5}$ & $\mathrm{~K}_{2} \mathrm{O}$ & $\mathrm{CaO}$ & $\mathrm{TiO}_{2}$ & $\mathrm{Fe}_{2} \mathrm{O}_{3}$ \\
\hline$\sigma(\mathrm{n}=8)$ & 0.04 & 2.41 & 0.56 & 2.66 & 0.01 & 0.39 & 0.39 & 0.00 & 0.06 \\
\hline Escultura & 0.82 & 5.41 & 6.16 & 84.88 & 0.31 & 1.61 & 0.62 & 0.04 & 0.15 \\
\hline$\sigma(\mathrm{n}=7)$ & 0.11 & 0.39 & 0.40 & 1.00 & 0.51 & 0.57 & 0.26 & & 0.03 \\
\hline Vajillas & 0.75 & 9.71 & 6.87 & 79.90 & 0.16 & 1.49 & 0.51 & 0.02 & 0.17 \\
\hline$\sigma(\mathrm{n}=9)$ & 0.13 & 2.60 & 2.60 & 2.56 & 0.05 & 0.41 & 0.35 & 0.02 & 0.10 \\
\hline
\end{tabular}




\section{La base de porcelana}

En la Tabla 1 se recogen los valores promedio y las desviaciones estándar $(\sigma)$ de la composición química de los tres tipos de piezas, vajilla, baldosas y escultura, encontrados en los restos estudiados. La composición de la base de porcelana se caracteriza por la alta concentración de magnesio $(\mathrm{MgO})$, que varía entre $5-6 \%$ en las piezas de escultura y entre $9-12 \%$ en la mayoría de las muestras de vajilla y de las baldosas. El valor máximo, $17 \%$, se alcanza en este último grupo. El contenido en sílice $\left(\mathrm{SiO}_{2}\right)$, entre 75 y $85 \%$, es marcadamente elevado y el de alúmina $\left(\mathrm{Al}_{2} \mathrm{O}_{3}\right)$, entre 4 y $7 \%$, pudiendo llegar al $10 \%$, es considerablemente bajo frente a la mayoría de las porcelanas de su época. Las concentraciones de $\mathrm{Fe}_{2} \mathrm{O}_{3}$ y $\mathrm{CaO}$ son inferiores al $1 \%$.

En la Figura 5 se representan los difractogramas de rayos $\mathrm{X}$ en los que se aprecian como fases cristalinas $\alpha$-cuarzo $\left(\mathrm{SiO}_{2}\right)$, $\alpha$-cristobalita $\left(\mathrm{SiO}_{2}\right)$ y protoenstatita $\left(\mathrm{MgSiO}_{3}\right)$ en los tres tipos de restos, baldosas, vajilla y escultura, estudiados. La intensidad de las líneas de la protoenstatita está claramente relacionada con el contenido en $\mathrm{MgO}$ de las muestras. Solo en los casos con mayor contenido de este óxido se ha detectado la clinoenstatita, que se formaría por transformación en el enfriamiento de la protoenstatita, la forma de alta temperatura del $\mathrm{MgSiO}_{3^{\prime}}$ que es una fase metaestable a temperatura ambiente.

La microestructura de la porcelana queda reflejada en la imagen de microscopía electrónica de barrido (Figura 6) tomada sobre la superficie de fractura de una muestra de vajilla. La microfotografía muestra los pequeños granos de $\alpha$-cuarzo con tamaño menor que $10 \mu \mathrm{m}$ y los agregados de cristales de protoenstatita, que se observan a mayores aumentos en la Figura 7, rodeados por una abundante fase vítrea.

En las superficies pulidas y atacadas con ácido fluorhídrico (Figura 8) se pueden observar los mismos elementos de la microestructura; los granos de $\alpha$-cuarzo transformados en los bordes en $\alpha$-cristobalita y los cristales de protoenstatita dispersos en la matriz vítrea. Lo mismo que en la superficie de fractura, en la superficie pulida se aprecia una red de grietas muy finas que rodean los granos de cuarzo. Las grietas se originan en el enfriamiento de la porcelana y son debidas a la transformación $\beta-\alpha$ del cuarzo, que tiene lugar a 573 ${ }^{\circ} \mathrm{C}$, e incluso a la transformación $\beta-\alpha$ de la cristobalita, que

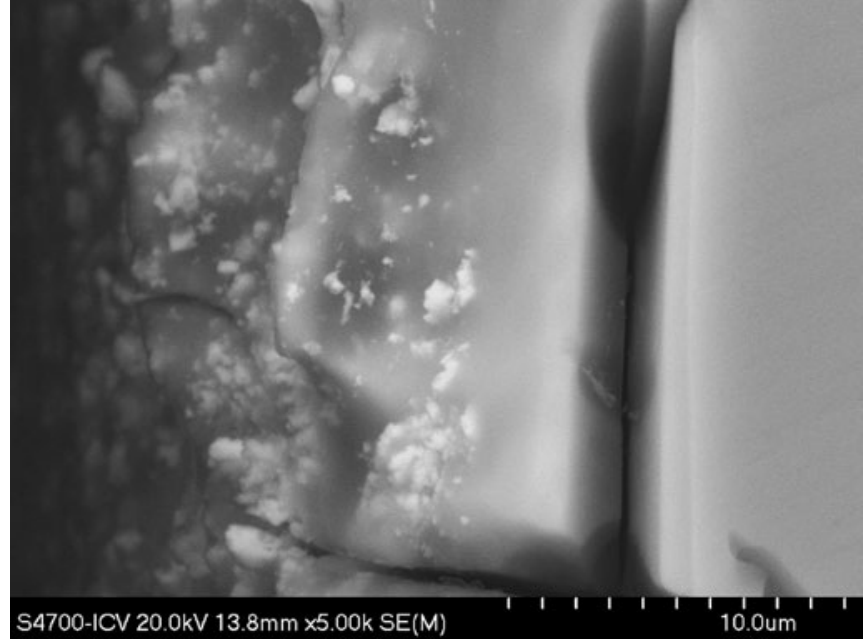

Figura 4. FE-SEM de la capa de color, con los microcristales de amarillo de Nápoles $\left(\mathrm{Pb}_{2} \mathrm{Sb}_{1-\mathrm{x}} \mathrm{Sn}_{\mathrm{x}} \mathrm{O}_{6.5}\right)$, separada por una grieta de la capa de vidriado.

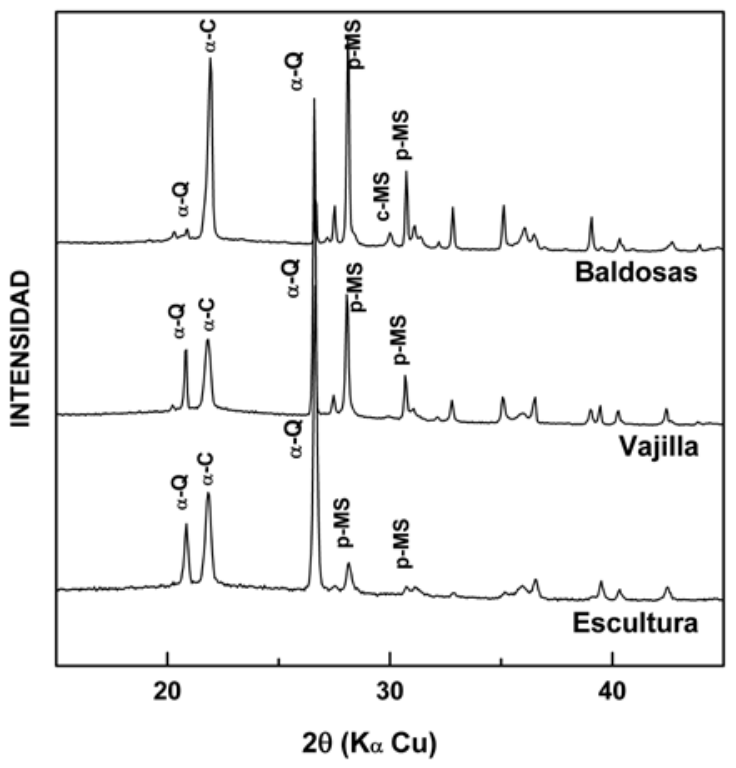

Figura 5. Difracción de rayos $X$ de los tres tipos de muestras estudiados, mostrando las fases cristalinas, $\alpha$-cuarzo $(\alpha-Q), \alpha$-cristobalita $(\alpha-\mathrm{C})$, protoenstatita (p-MS) y clinoenstatita (c-MS) presentes en la porcelana.

TABLA 2. COMPOSICIÓN PROMEDIO Y DESVIACIÓN ESTÁNDAR DE LOS VIDRIADOS DETERMINADOS MEDIANTE XRF Y SEM-EDS

\begin{tabular}{|c|c|c|c|c|c|c|c|c|c|c|c|c|c|}
\hline & $\mathrm{Na}_{2} \mathrm{O}$ & $\mathrm{MgO}$ & $\mathrm{Al}_{2} \mathrm{O}_{3}$ & $\mathrm{SiO}_{2}$ & $\mathrm{P}_{2} \mathrm{O}_{5}$ & $\mathrm{SO}_{3}$ & $\mathrm{~K}_{2} \mathrm{O}$ & $\mathrm{CaO}$ & $\mathrm{Fe}_{2} \mathrm{O}_{3}$ & $\mathrm{Rb}_{2} \mathrm{O}$ & SrO & $\mathrm{PbO}$ & $\mathrm{TiO}_{2}$ \\
\hline XRF & 1.68 & 0.56 & 17.70 & 63.24 & 0.35 & 0.07 & 8.56 & 1.06 & 0.16 & 0.09 & 0.01 & 0.04 & 0.02 \\
\hline$\sigma(\mathbf{n}=10)$ & 0.32 & 0.32 & 0.89 & 2.55 & 0.12 & 0.05 & 1.54 & 0.43 & 0.20 & 0.14 & 0.00 & 0.07 & 0.00 \\
\hline SEM-EDS & 1.48 & 1.02 & 17.03 & 70.04 & & & 10.40 & 1.97 & 0.10 & & & & \\
\hline$\sigma(\mathbf{n}=8)$ & 0.56 & 0.25 & 0.96 & 2.37 & & & 3.27 & 1.03 & 0.08 & & & & \\
\hline
\end{tabular}




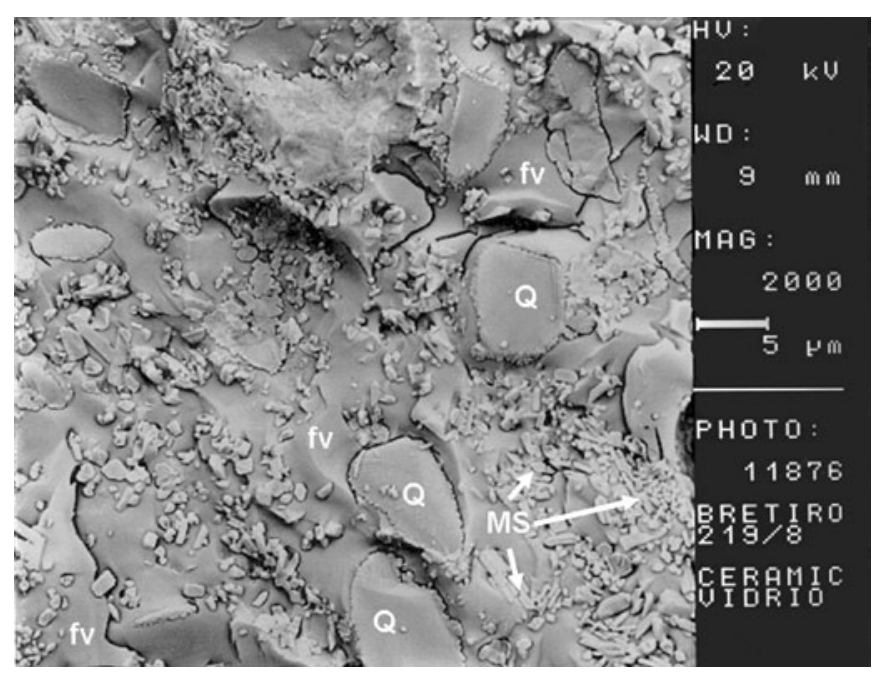

Figura 6. Microfotografía de MEB mostrando los cristales de cuarzo (Q) rodeados de abundante fase vítrea (fv) y agregados dispersos de cristales prismáticos de protoenstatita (MS). Tomada por Salvador de Aza en 2001.

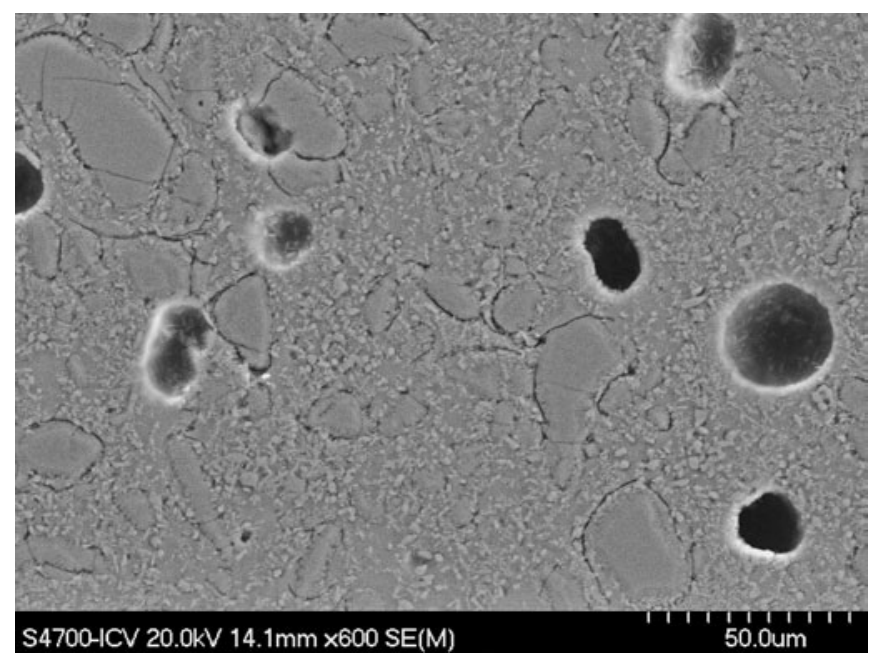

Figura 8. Microfotografía de (FE-SEM) de la superficie atacada mostrando los pequeños cristales de $\mathrm{MgSiO}_{3}$ y los granos de cuarzo rodeados de grietas circulares.

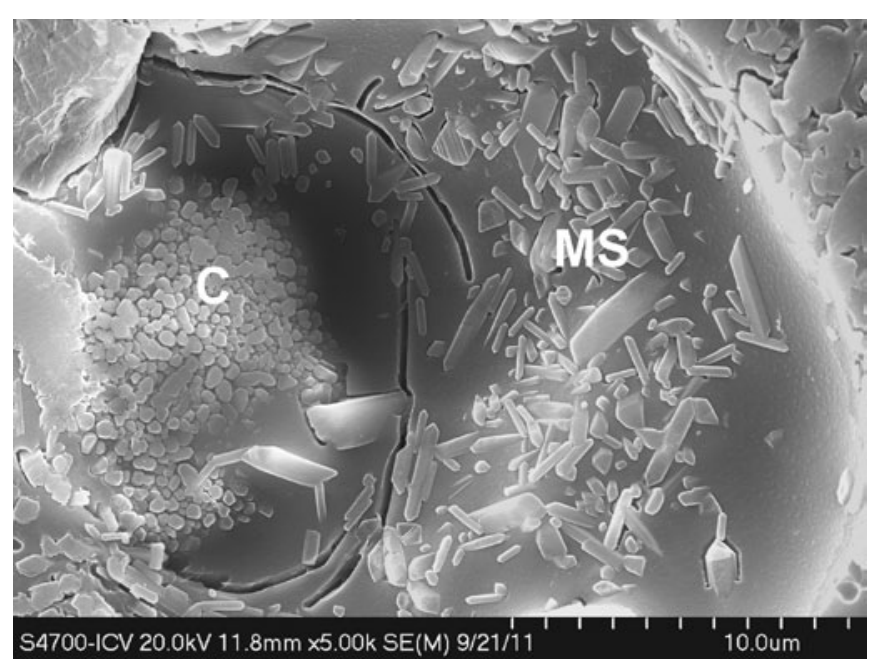

Figura 10. Microfotografía (FE-SEM) de los cristales en forma de prismas de proesntatita (MS) y de rosetas de $\alpha$-cristobalita (C) en el interior de un poro.

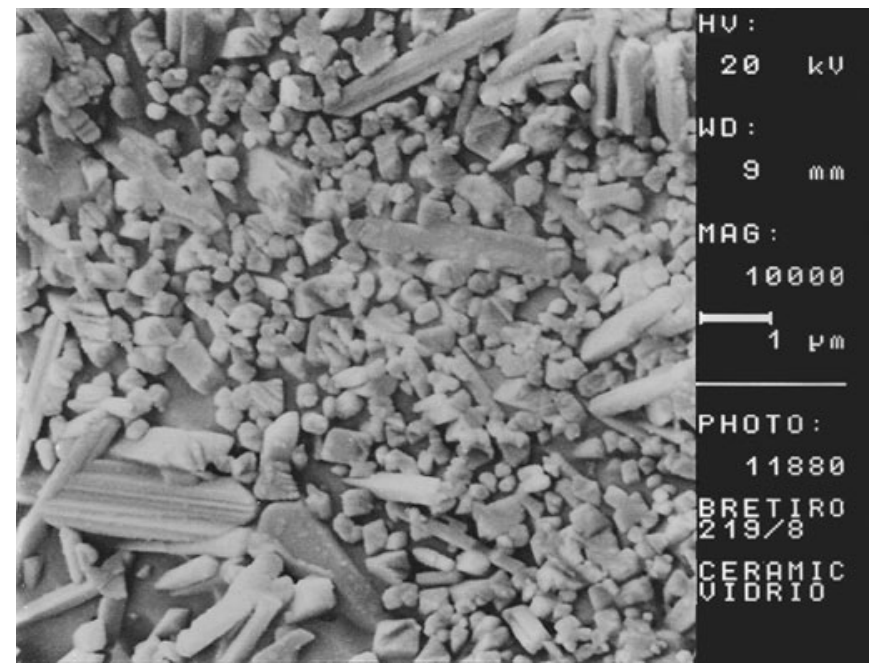

Figura 7. Microfotografía de MEB mostrando los cristales prismáticos de protoenstatita junto con cristales de aspecto cúbico de $\alpha$-cristobalita. Tomada por Salvador de Aza en 2001.

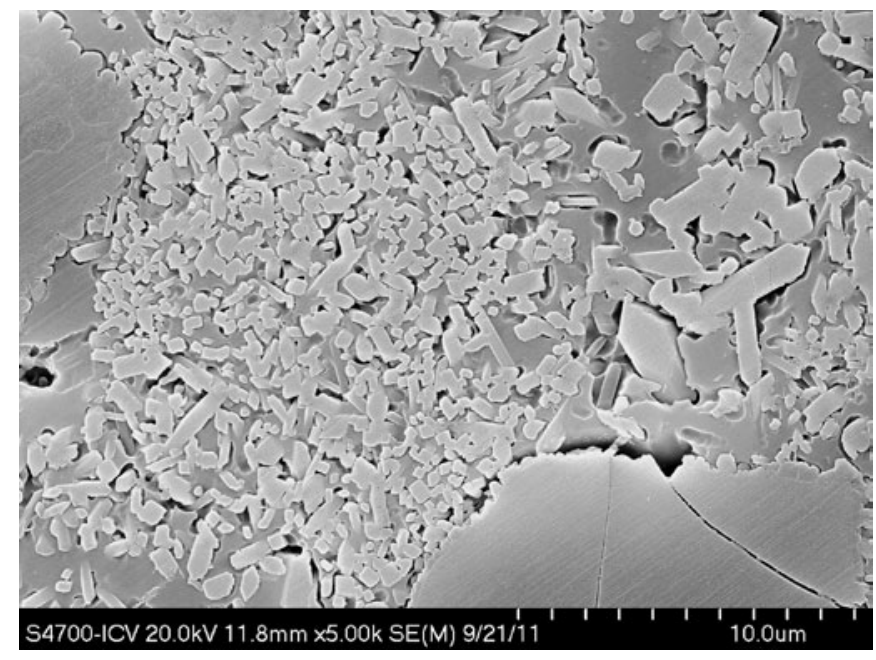

Figura 9. Agregado orientado de cristales de proenstatita (MS) y cristales de cristobalita (C) formados en la superficie de los granos de cuarzo (Q).

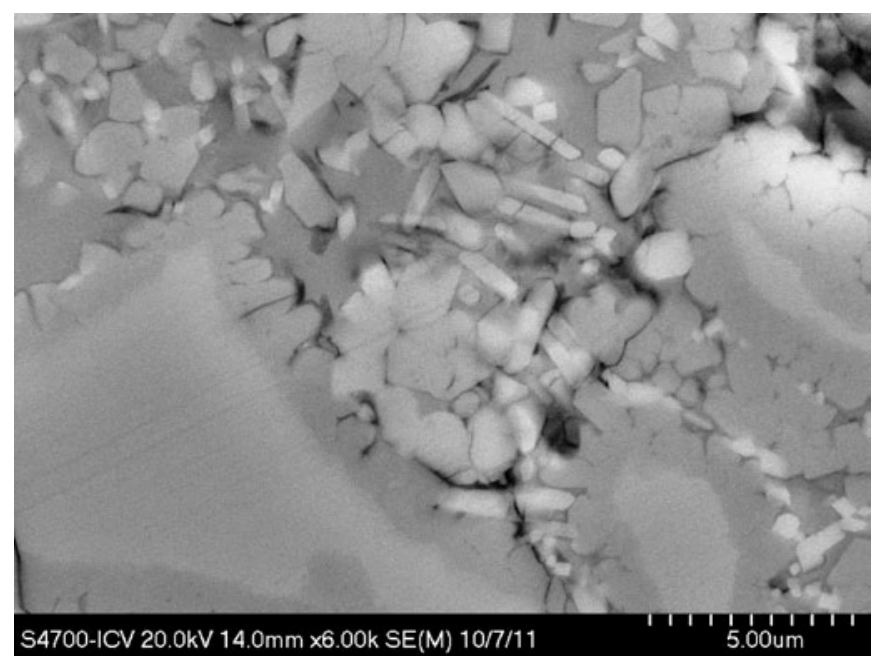

Figura 11. Nucleación de cristales de $\alpha$-cristobalita en la superficie de los granos de $\alpha$-cuarzo. 
se produce alrededor de los $265^{\circ} \mathrm{C}$. Como consecuencia de estas grietas circulares, los granos de cuarzo se arrancan en el pulido y aparentemente la microestructura es más porosa. En cualquier caso se trata de porosidad cerrada, no superando la porosidad abierta el 2-3\%.

Los cristales de protoenstatita aparecen diseminados en toda la matriz, aunque forman aglomerados altamente orientados en los volúmenes que originariamente ocupaban los granos de sepiolita (Figura 9). Estas zonas tienen una relación $\mathrm{Mg} / \mathrm{Si}$ más próxima a la de la sepiolita que a la del $\mathrm{MgSiO}_{3^{\prime}}$ lo que indicaría la probable cristalización en estas zonas de la cristobalita junto con la protoenstatita. En la Figura 10 se observa más claramente, en un poro, la diferente morfología de los cristales prismáticos de la protoenstatita creciendo en la fase vítrea y los cristales en forma de rosetas de la $\alpha$-cristobalita cubriendo un grano de cuarzo. Los datos de EDS confirman la naturaleza de los dos tipos de cristales observados. En la Figura 11, en una muestra electrodada con grafito, se puede ver con mayor contraste la cristalización de la $\alpha$-cristobalita, rosetas de aproximadamente $0.5 \mu \mathrm{m}$ de diámetro, sobre la superficie de los granos de cuarzo.

Entre los restos de baldosas se ha encontrado un conjunto de fragmentos cuya composición difiere radicalmente de la porcelana de Sureda. Las características químico-físicas de estas muestras indican que habrían sido fabricadas en las etapas iniciales de Buen Retiro. Su estudio no se incluye en este trabajo.

\section{El vidriado}

En la Tabla 2 se recogen los análisis mediante XRF y SEMEDS de los vidriados estudiados en algunas piezas de vajilla y algunas baldosas. Las piezas de escultura son bizcochos y no están por tanto vidriadas. El análisis elemental mediante XRF y SEM-EDS indica la ausencia de plomo $(\mathrm{PbO})$, como característica fundamental de las cubiertas en la porcelana de Sureda, tanto en las piezas de vajilla como en las baldosas. La composición, expresada en equivalentes molares, $0.9 \mathrm{RO}$ - $1.0 \mathrm{Al}_{2} \mathrm{O}_{3}-6.2 \cdot \mathrm{SiO}_{2}$ en la que $\mathrm{RO}$ incluye todos los óxidos fundentes (alcalinos, alcalinoterreos), se aproxima a la fórmula del feldespato, $\mathrm{K}_{2} \mathrm{O} \cdot \mathrm{Al}_{2} \mathrm{O}_{3} \cdot 6 \mathrm{SiO}_{2}^{42}$.

Los colores sobre cubierta.

Las baldosas y una taza fueron los únicos restos que presentaban una capa coloreada. Los colores, como se observa en la Figura 12 están aplicados sobre el vidriado y consisten en agregados cristalinos de los pigmentos dispersos en una fase vítrea rica en $\mathrm{PbO}$. En el análisis mediante difracción de rayos $\mathrm{X}$ en ángulo rasante, realizado sobre una baldosa color salmón (Figura 13), se identifican las líneas de difracción del oro metálico $(\mathrm{Au})$, la casiterita $\left(\mathrm{SnO}_{2}\right)$ y el pirocloro $\left(\mathrm{Pb}_{2} \mathrm{SnSbO}_{6.5}\right)$, indicando la complejidad de los esmaltes. El análisis de área mediante SEM-EDS realizado en la sección observada en la Figura 12 confirma la presencia de estos elementos, siendo los pigmentos utilizados el púrpura de Cassius, oro coloidal precipitado con estaño, y el amarillo de Nápoles. La gama de colores de las muestras encontradas en la prospección arqueológica se reduce a los granates, rojos y violetas, basados en el púrpura de Cassius, y a los amarillos basados en el antimoniato de plomo, $\mathrm{Pb}_{2} \mathrm{Sb}_{1-\mathrm{x}} \mathrm{M}_{\mathrm{x}} \mathrm{O}_{6.5}(\mathrm{M}=\mathrm{Sn}$, $\mathrm{Fe} . . .{ }^{40}$. Los microcristales de antimonato en el vidrio rico en

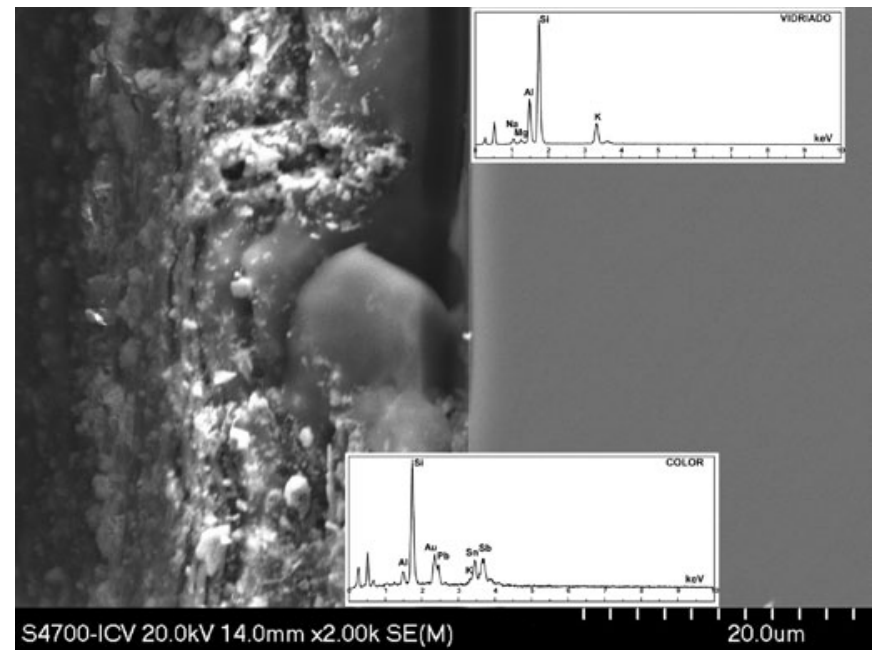

Figura 12. Microfotografía (FE-SEM) y microanálisis EDS del esmalte y del vidriado.

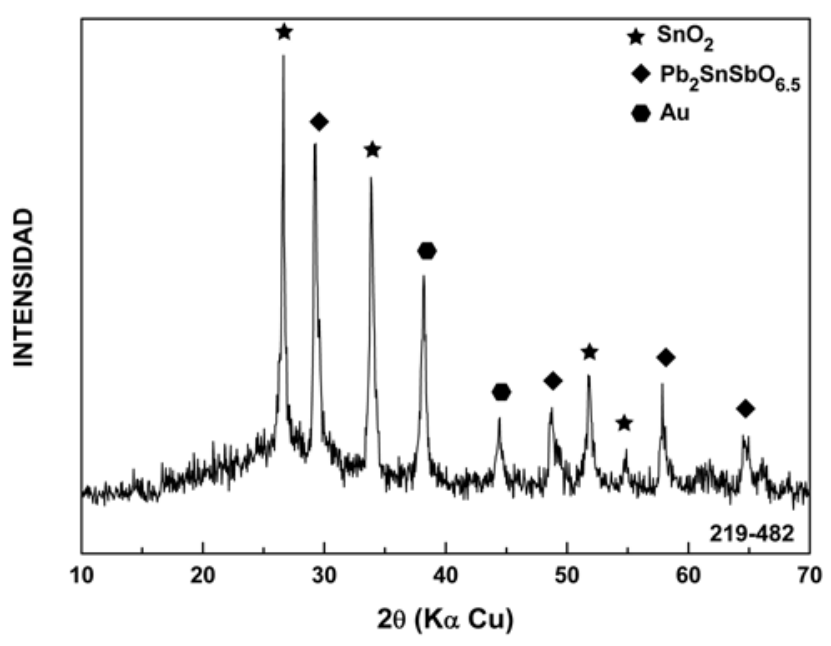

Figura 13. Difracción de rayos $X$ en ángulo rasante de un esmalte basado en púrpura de Cassius y amarillo de Nápoles.

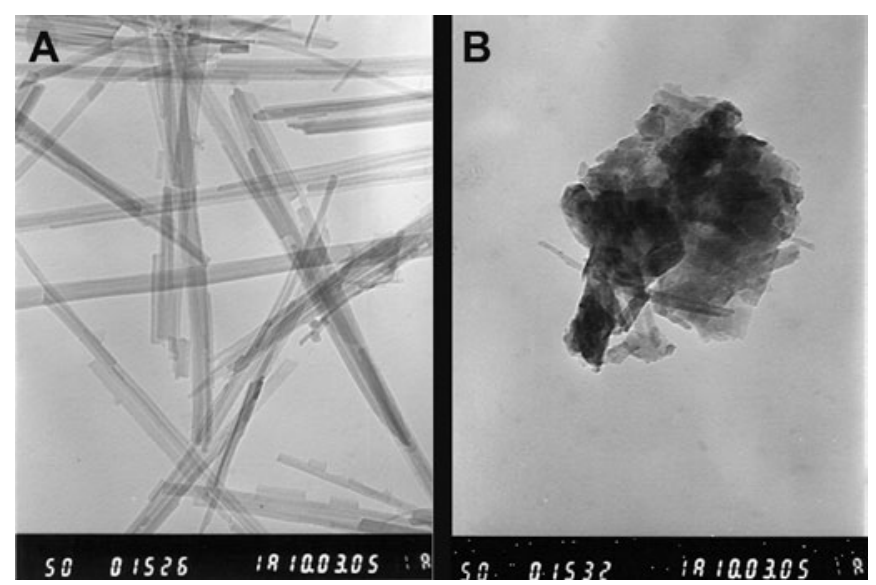

Figura 14. Morfología de la sepiolita (A) y la esmectita magnésica (B) observadas por TEM. 


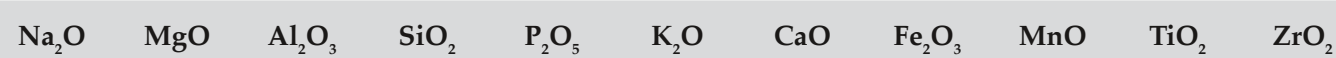

\begin{tabular}{lccccccccccc} 
ARC. SEPIOLÍTICA & 0.29 & 22.73 & 3.2 & 60.28 & 0.07 & 0.98 & 0.54 & 0.81 & 0.04 & 0.14 & 0.01 \\
& & & & & & & & & & & \\
BENTONITA MAG. & 0.19 & 24.18 & 4.96 & 52.22 & 0.10 & 0.93 & 2.62 & 1.63 & 0.04 & 0.2 & 0.01 \\
\hline
\end{tabular}

$\mathrm{PbO}$ pueden observarse en la Figura 4. Los tonos más claros de violeta y amarillo que presentan las piezas que no guardan similitud con las baldosas colocadas en la Casita del Labrador de Aranjuez responden a este mismo esquema de composición y estructura.

\section{Las materias primas}

El estudio de difracción de rayos $X$ de la denominada "Arcilla Sepiolitica" indica un contenido en sepiolita, $\mathrm{Mg}_{8} \mathrm{Si}_{12} \mathrm{O}_{30}(\mathrm{OH})_{4}\left(\mathrm{H}_{2} \mathrm{O}\right)_{4} 8 \mathrm{H}_{2} \mathrm{O}$, cercano al $90 \%$ con pequeñas cantidades de cuarzo y calcita y trazas de feldespatos. Su superficie específica es $258 \mathrm{~m}^{2} / \mathrm{g}$.

El estudio por XRD de la "Bentonita Magnésica" ha mostrado que, además de esmectita trioctaédrica $(\sim 60 \%)$, $\left(\mathrm{Ca}_{0,5}, \mathrm{Na}\right)_{033}(\mathrm{Mg}, \mathrm{Fe})_{3} \mathrm{Si}_{4} \mathrm{O}_{10}(\mathrm{OH})_{2} \cdot \mathrm{n}\left(\mathrm{H}_{2} \mathrm{O}\right)$, contiene importantes cantidades de sepiolita $(25-30 \%)$ y pequeñas cantidades de dolomita, cuarzo y calcita. Utilizando el método de agregados orientados se detectó además la presencia de micas, con estructura probablemente dioctaédrica dadas las características geológicas de la Cuenca del Tajo ${ }^{43}$. Su superficie específica es $195 \mathrm{~m}^{2} / \mathrm{g}$.

En la Figura 14 las micrografías obtenidas por TEM muestran la diferente morfología de la sepiolita y la esmectita magnésica. La sepiolita es un mineral arcilloso de naturaleza acicular que en la "Arcilla Sepiolítica" (Figura 14A) se presenta en fibras largas y finas, escasamente aglomeradas, con longitudes de hasta $100 \mu \mathrm{m}$. La "Bentonita Magnésica"
(Figura 14B) consiste en laminillas muy finas $(<2 \mu \mathrm{m})$ de esmectita, que tienden a formar pequeños aglomerados, y fibras de sepiolita que forman husillos o manojos de fibras cortas $(\sim 40 \mu \mathrm{m})$, aunque se detectan algunas fibras largas aisladas $(\sim 100 \mu \mathrm{m})$ similares a las observadas en la "Arcilla Sepiolitica".

El estudio simultaneo por análisis térmico diferencial y termogravimétrico confirma la composición mineralógica observada por XRD. En la Figura 15, la curva TDA correspondiente a la "Arcilla Sepiolitica" muestra los cuatro efectos endotérmicos a 116, 312, 503 y $824{ }^{\circ} \mathrm{C}$ y el exotérmico a $840{ }^{\circ} \mathrm{C}$ que son característicos de la sepiolita ${ }^{44}$. Los tres primeros están asociados a la pérdida del agua zeolítica y del agua de cristalización ${ }^{45}$ y el bucle de alta temperatura a la destrucción de la red de la sepiolita anhidra, $\mathrm{Mg}_{8} \mathrm{Si}_{12} \mathrm{O}_{30}(\mathrm{OH})_{4^{\prime}}$ y la formación de enstatita, $\mathrm{MgSiO}_{3}{ }^{46,47}$. Los ensayos se realizaron con el material natural, siendo la pérdida de peso total de $17 \%$.

En la "Bentonita Magnésica" (Figura 16) el fuerte efecto endotérmico a $110{ }^{\circ} \mathrm{C}$, originado por la pérdida del agua interlaminar, y el bucle endo - exo a $820-840{ }^{\circ} \mathrm{C}$, debido a destrucción de la estructura del filosilicato y la formación de enstatita, son los característicos de las esmectitas trioctaédricas $^{48}$. La débil inflexión de las curvas DTA y TG, a $705^{\circ} \mathrm{C}$ se debe a la descarbonatación de la calcita y la dolomita. El ensayo se realizó con el material natural, siendo la pérdida de peso total de $16 \%$.

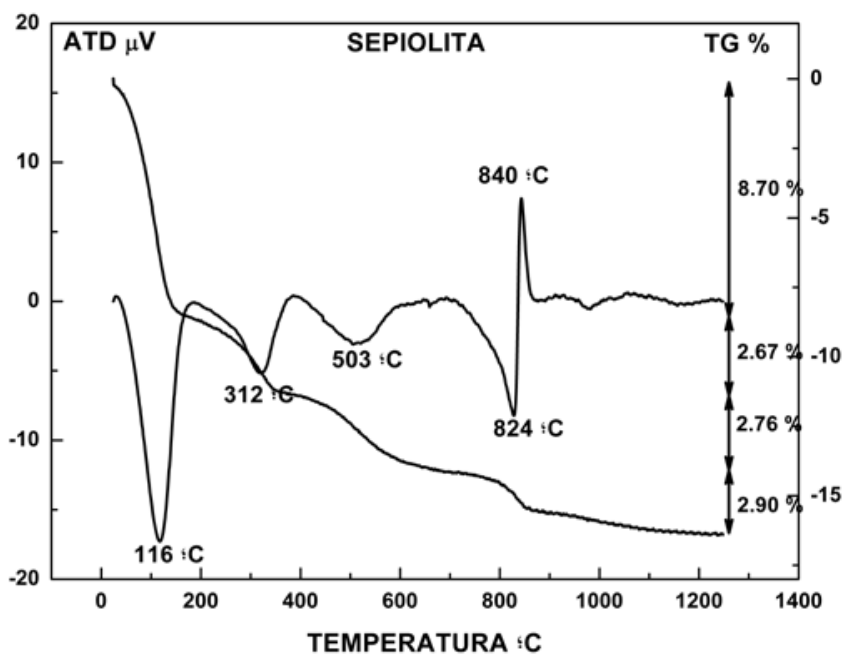

Figura 15. Análisis térmico (TDA-TG) de la "Arcilla Sepiolítica".

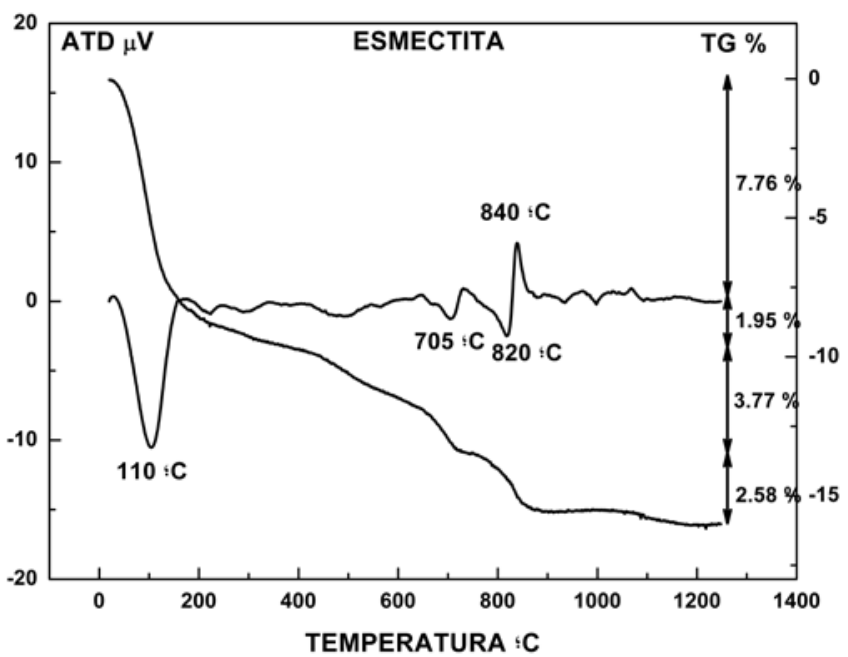

Figura 16. Análisis térmico (TDA-TG) de la "Bentonita Magnésica". 
El análisis elemental de ambas arcillas, Tabla 3, concuerda razonablemente con la mineralogía determinada por XRD y DTA-TG. De las dos arcillas estudiadas, la "Bentonita Magnésica" presenta un nivel más elevado de impurezas. La inclusión de la "Bentonita Magnésica", como materia prima, en la formulación de la porcelana daría lugar a contenidos de $\mathrm{CaO}$ y $\mathrm{Fe} 2 \mathrm{O} 3$ superiores a los valores analizados en las muestras arqueológicas.

Los datos de DTA indican que la descomposición las dos arcillas y la formación de la enstatita tiene lugar entre 820 y $840{ }^{\circ} \mathrm{C}$, sin embargo su evolución a alta temperatura muestra diferencias considerables. El seguimiento mediante difracción de rayos $\mathrm{X}$ de las arcillas tratadas entre 900 y $1300{ }^{\circ} \mathrm{C}$ durante 2, 24 y 48 horas, indica que la transformación de enstatita protoenstatita del $\mathrm{MgSiO}_{3}$ comienza a $1200{ }^{\circ} \mathrm{C}$. En la sepiolita se observa además la presencia de $\alpha$-cristobalita en las muestras tratadas a $1000{ }^{\circ} \mathrm{C}$, permaneciendo estable esta fase hasta $1250-1300{ }^{\circ} \mathrm{C}$. En la bentonita no se detecta cristobalita cuando el tratamiento es corto; para tiempos más largos, 48 horas, aparece en muy pequeña cantidad y en un rango de temperatura menor, $1050-1100{ }^{\circ} \mathrm{C}$.

Lo más destacable de las dilatometrías de la "Arcilla Sepiolítica" y la "Bentonita Magnésica" es la fuerte contracción que sufren las dos materias primas a partir de $900{ }^{\circ} \mathrm{C}$. La variación en la longitud total, entre 25 y $1300^{\circ} \mathrm{C}$, de la bentonita es del $35 \%$ y la de la sepiolita del $61 \%$, lo que dificulta la preparación de pastas cerámicas con estas arcillas.

Tras el tratamiento a alta temperatura $\left(1200-1300^{\circ} \mathrm{C}\right)$, en el enfriamiento la "Bentonita Magnésica" está constituida por abundante vidrio y cristales de protoenstatita, mientras que la "Arcilla Sepiolitica" lo está por protoenstatita, cristobalita y una fase vítrea.

\section{Reproducción de la porcelana.}

La pasta de porcelana se preparó siguiendo la receta de Bartolomé Sureda ${ }^{49}$, calcinando el $70 \%$ de la arcilla a $1250{ }^{\circ} \mathrm{C}$ (gran fuego) durante 6 horas para evitar la enorme contracción que sufre la sepiolita en el proceso de cocción de la porcelana. Como materias primas se utilizaron, además de la "Arcilla Sepiolítica", un cuarzo y un feldespato similares a los que actualmente se emplean en los procesos industriales. La composición de la pasta elaborada en el laboratorio se mantiene dentro de los márgenes de composición de las muestras estudiadas con un $10.9 \%$ de $\mathrm{MgO}, 4.5 \%$ de $\mathrm{Al}_{2} \mathrm{O}_{3^{\prime}}$ $80.0 \%$ de $\mathrm{SiO}_{2}, 1.8 \%$ de $\mathrm{K}_{2} \mathrm{O}, 0.7 \%$ de $\mathrm{Na}_{2} \mathrm{O}, 0.5 \%$ de $\mathrm{CaO}$ y $0.5 \%$ de $\mathrm{Fe}_{2} \mathrm{O}_{3}$.

La curva de sinterización dinámica a $5^{\circ} \mathrm{C} / \mathrm{min}$ en la Figura 17 muestra que la sinterización comienza a $850{ }^{\circ} \mathrm{C}$ sufriendo una ralentización entre 1000 y $1100{ }^{\circ} \mathrm{C}$. Desde esta temperatura y hasta $1350{ }^{\circ} \mathrm{C}$ la curva mantiene un hábito constante con la máxima velocidad de contracción a $1265{ }^{\circ} \mathrm{C}$, pudiéndose establecer un intervalo muy amplio, $1100-1350{ }^{\circ} \mathrm{C}$, para la temperatura de maduración de la pasta. A partir de $1350^{\circ} \mathrm{C}$, la curva indica un comportamiento menos estable y por último hacia $1375^{\circ} \mathrm{C}$ el material colapsa.

En la Figura 18 se muestran los difractogramas de rayos $X$ de la porcelana reproducida, sinterizada a $1250{ }^{\circ} \mathrm{C}$ durante 24 horas, y de una de las baldosas de la Casita del Labrador de Aranjuez. La similitud en las intensidades de las líneas de difracción es grande y más considerando el amplio margen de composición mineralógica que se ha encontrado tanto en las primeras muestras estudiadas ${ }^{50}$, como en las baldosas de Aranjuez y de la excavación del Retiro ${ }^{40}$.

\section{DISCUSIÓN}

Los resultados de la caracterización físico-química de la porcelana que fabricó Sureda en la última etapa de Buen Retiro muestran que los principales óxidos constituyentes del material son sílice, $\mathrm{SiO}_{2^{\prime}}$ magnesia, $\mathrm{MgO}$, alúmina, $\mathrm{Al}_{2} \mathrm{O}_{3^{\prime}}$ y una pequeña fracción de óxidos alcalinos, $\mathrm{K}_{2} \mathrm{O}$ y $\mathrm{Na}_{2} \mathrm{O}$, presentando como fases cristalinas, $\alpha$-cuarzo, $\alpha$-cristobalita y protoenstatita.

Las composiciones se repiten dentro de márgenes pequeños en los restos de vajilla, escultura y baldosas encontrados en el

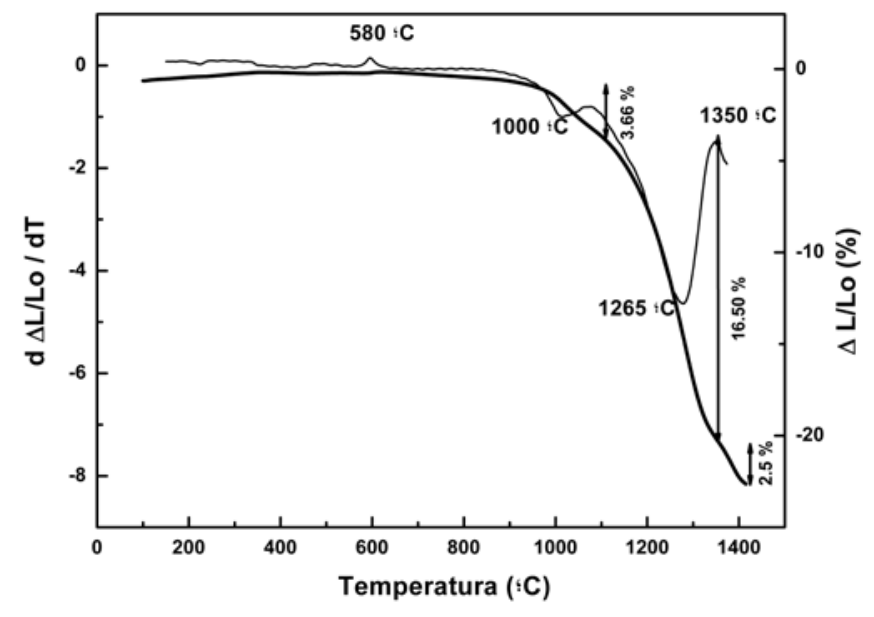

Figura 17. Dilatometría y curva derivada de la sinterización de una pasta preparada a partir de sepiolita, cuarzo y feldespato.

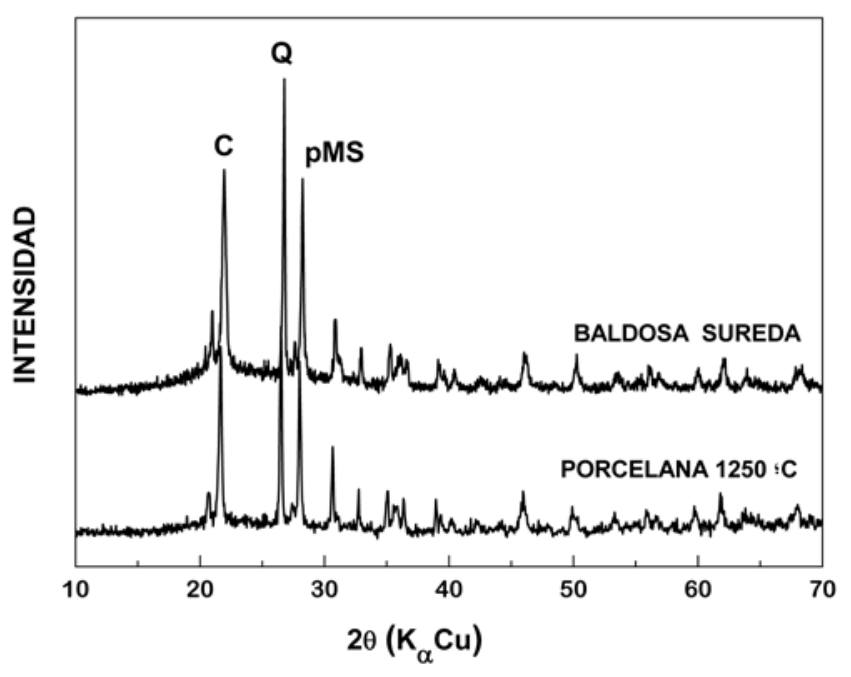

Figura 18. Difracción de rayos $X$ de una baldosa de Sureda y de la reproducción de la porcelana cocida a $1250{ }^{\circ} \mathrm{C}$, identificándose las mismas fases cristalinas; $\alpha$-cristobalita (C), $\alpha$-cuarzo (Q) y protoenstatita (pMS). 
Con variaciones respecto a las cantidades de los componentes, en un manuscrito de Manuel de Agreda, último director de porcelana y colores de Retiro, se indica otra fórmula $^{65}$

\section{Pasta de Porcelana}

\section{4 partes Quarzo de Galapagar}

2 y media Feldespato descompuesto del Majuelo de Laso, media lega antes de Colmenar viejo. 2 Arcilla magnesiana de una arroyada al norte de la huerta Zabala, pasado la Fuente del Caño Gordo

Frente al $40 \%$ de arcilla que considera la fórmula de Sureda, ésta de Ágreda tan solo contiene un $24 \%$ de arcilla y contenidos mayores de feldespato, $29 \%$, y de cuarzo, 47 $\%$. La utilización de una u otra fórmula, el origen, aunque Vallecas y la Fuente de Caño Gordo (Moratalaz) ${ }^{66}$ sean lugares próximos, y la composición de la sepiolita y del resto de las materias primas pueden justificar las diferencias observadas en el contenido en $\mathrm{MgO}$ de las muestras estudiadas. Aunque el aporte de arcilla sea menor en esta receta, la inclusión de la totalidad de la sepiolita sin calcinar, con su considerable contracción, hace poco factible esta fórmula.

\section{Materias primas}

La formulación de la porcelana de Sureda incluye como materias primas la sepiolita, el feldespato y el cuarzo, siendo la sepiolita, la "tierra de Vallecas", el elemento diferenciador de esta porcelana.

Las características que se han determinado en la sepiolita de Vallecas indican con toda seguridad que este mineral fue el componente "plástico y no fusible al fuego de la porcelana", según la definición en los tratados sobre la porcelana de los siglos XVIII y XIX, que utilizó Sureda en la elaboración de la porcelana. Brongniart señala que la "magnesite de Vallecas", seguramente una muestra recibida de Sureda, contenía $24 \%$ de $\mathrm{MgO}, 54 \%$ de $\mathrm{SiO}_{2}$ y $20 \%$ de $\mathrm{H}_{2} \mathrm{O}^{67}$, análisis que concuerda con los datos de TDA y XRF realizados en este trabajo. El término "magnesite" incluía entonces un grupo más amplio de minerales, entre los que Brongnart nombra las sepiolitas de Vallecas Madrid) y Cabañas (Toledo), formados por silicatos, y a veces carbonatos, de magnesio hidratados ${ }^{64}$.

Actualmente se sabe que entre Vicálvaro y Vallecas se encuentra un yacimiento de sepiolita $^{68}$ de gran calidad y homogeneidad ${ }^{69}$. Sin embargo, aunque los yacimientos de la Cuenca del Tajo contienen aproximadamente el $70 \%$ de la reserva mundial de sepiolita ${ }^{70}$, no es esta la única arcilla magnésica existente en el entono Vicálvaro - Vallecas. Las explotaciones de sepiolita en la Cuenca Neógena de Madrid, incluyen secuencias que oscilan entre 10 y $50 \mathrm{~m}$ de potencia, en que las esmectitas trioctaédricas de carácter magnésico ${ }^{71}$ (saponita ${ }^{72} \mathrm{o}$ estevensita ${ }^{73}$ ) alternan con sepiolita $\mathrm{y} / \mathrm{o}$ minerales micáceos ${ }^{74}$.

Es probable, como se ha dicho, que Sureda ensayara "la tierra de Vallecas" durante su estancia en París e incluso que esta tierra hubiera sido utilizada en las primeras etapas de la Fábrica del Buen Retiro. La primera noticia que ha llegado hasta nosotros de la "piedra de Vicálvaro" como un mineral de sílice $\left(\mathrm{SiO}_{2}\right)$ y magnesia $(\mathrm{MgO})$ es de un catedrático del Real Colegio de S. Carlos, traductor de la Nueva Nomenclatura Química $^{75}$, que en un tratado de Química de 1803 indica que ya había ensayado su utilización en la obtención de la magnesia, para uso médico, veinte años antes ${ }^{76}$. Herrgen nombra en el género de los minerales magnésicos "la espuma de mar de Vallecas", a la que también llamaban "piedra loca"77 y publica en los Anales de Ciencias, del que era editor, un análisis de la "espuma de mar ... de Vallecas ... que sirve para fabricar pipas y hornillas" con un $25 \%$ de magnesia y un $51 \%$ de sílice ${ }^{78}$.

Así, cuando Sureda llega a Buen Retiro en 1803, la "tierra de Vallecas" era un mineral conocido, por lo menos a nivel local, y más asequible que el caolín del que apenas se habían encontrado yacimientos en España. La sepiolita hoy no tiene aplicación en la industria cerámica al ser un mineral con un alto valor añadido por su aplicación como absorbente y su capacidad para integrarse en distintos tipos de materiales nanoestructurados ${ }^{79}$.
A

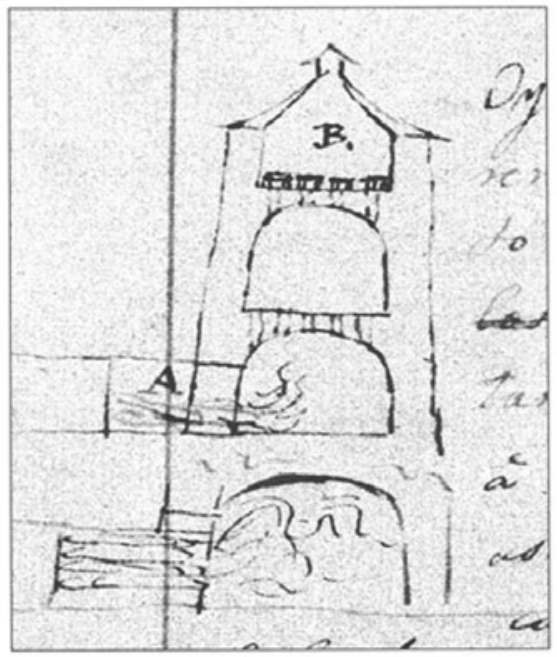

B

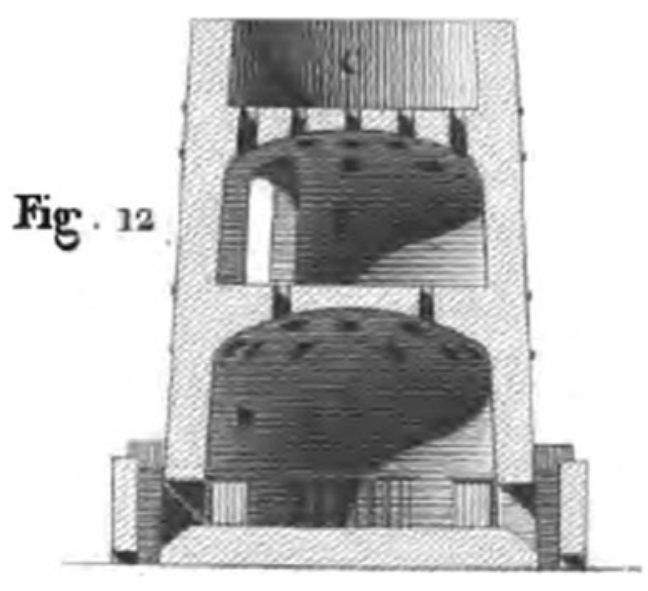

Figura 19. Perfil e interior de los hornos para porcelana dura de Sèvres. (A) apuntes de Sureda (1802) ${ }^{37}$. (B) diseño de Brongniart (1804) ${ }^{83}$. 
El feldespato se identificaba en todos los tratados de mineralogía de finales del siglo XVIII con el "petun-tsé", el componente fusible necesario para fabricar la porcelana. Herrgen clasificó el feldespato en el grupo de los materiales silíceos y nombra yacimientos en San Lorenzo, S. Ildefonso, Buytrago, Molar y Toledo ${ }^{80}$. En esta misma obra ${ }^{81}$ se cita otro yacimiento en Bailén conocido desde 1785. Sureda no indica la procedencia del feldespato utilizado en Buen Retiro, aludiendo solo a que años antes habían sido descubiertos algunos yacimientos en España ${ }^{53}$. El análisis actual del feldespato del Majuelo de Laso (Madrid), que cita Ágreda, contiene 7 - $14 \%$ de $\mathrm{K}_{2} \mathrm{O}, 1$ - 5 de $\mathrm{Na}_{2} \mathrm{O}$ y $14-19 \%$ de alúmina, siendo las fases detectadas microclina y ortoclasa ${ }^{66}$.

El cuarzo de Galapagar a que aluden las fórmulas fue estudiado también en el primer proyecto de Buen Retiro, encontrándose un contenido en $\mathrm{SiO}_{2}$ superior al $99 \%$ y $\alpha$-cuarzo como única fase cristalina ${ }^{66}$.

\section{Desarrollo mineralógico y microestructural de la porcelana.}

Los documentos de Sureda no aportan ningún dato respecto al procesamiento de las materias primas, ni al conformado de las piezas, ni a la cocción de la porcelana en la Fábrica de Buen Retiro. En el Cuaderno de Notas se reproducen los apuntes tomados en Sèvres sobre los hornos de cocer la porcelana dura (Figura 19A) y la duración del proceso. El calentamiento duraba 12 horas hasta alcanzar la temperatura requerida, que se mantenía durante $18-20$ horas $^{37}$. La carga era enorme $y$, dada su gran inercia, los hornos tardaban entre 3 y 4 días en enfriarse $^{82}$. En esta misma época, San Christobal y Garriga ${ }^{83}$ reconocen los prometedores resultados de Sureda y hacen una descripción más precisa sobre la fabricación la porcelana dura y el horno que diseñó y utilizaba Brongniart en Sèvres (Figura 19B) en los primeros años del siglo XIX.

La temperatura, el tiempo y la atmósfera del horno determinan las reacciones químicas y el desarrollo de la microestructura de la porcelana.

Así, la primera reacción que tiene lugar en la cocción de la porcelana es la pérdida de agua de la arcilla, que, de acuerdo con el análisis térmico (Figuras 15 y 16), en la sepiolita tiene lugar en cuatro etapas ${ }^{44}$ :

$\begin{array}{lll}\mathrm{Mg}_{8} \mathrm{Si}_{12} \mathrm{O}_{30}(\mathrm{OH})_{4}\left(\mathrm{H}_{2} \mathrm{O}\right)_{4} \cdot 8 \mathrm{H}_{2} \mathrm{O} & \rightarrow \mathrm{Mg}_{8} \mathrm{Si}_{12} \mathrm{O}_{30}(\mathrm{OH})_{4}\left(\mathrm{H}_{2} \mathrm{O}\right)_{4}+8 \mathrm{H}_{2} \mathrm{O} & 116^{\circ} \mathrm{C} \\ \mathrm{Mg}_{8} \mathrm{Si}_{12} \mathrm{O}_{30}(\mathrm{OH})_{4}\left(\mathrm{H}_{2} \mathrm{O}\right)_{4} & \rightarrow \mathrm{Mg}_{8} \mathrm{Si}_{12} \mathrm{O}_{30}(\mathrm{OH})_{4}\left(\mathrm{H}_{2} \mathrm{O}\right)_{2}+2 \mathrm{H}_{2} \mathrm{O} & 312^{\circ} \mathrm{C} \\ \mathrm{Mg}_{8} \mathrm{Si}_{12} \mathrm{O}_{30}(\mathrm{OH})_{4}\left(\mathrm{H}_{2} \mathrm{O}\right)_{2} & \rightarrow \mathrm{Mg}_{8} \mathrm{Si}_{12} \mathrm{O}_{30}(\mathrm{OH})_{4}+2 \mathrm{H}_{2} \mathrm{O} & 503^{\circ} \mathrm{C} \\ \mathrm{Mg}_{8} \mathrm{Si}_{12} \mathrm{O}_{30}(\mathrm{OH})_{4} & \rightarrow 8 \mathrm{MgSiO}_{3}+4 \mathrm{SiO}_{2}+2 \mathrm{H}_{2} \mathrm{O} & 824^{\circ} \mathrm{C}\end{array}$

En la zona de baja temperatura, por debajo de $200^{\circ} \mathrm{C}$ se pierde el agua higroscópica y el agua zeolítica, que está en los canales de la estructura enlazada por puentes de hidrógen ${ }^{47}$. Entre 250 y $400{ }^{\circ} \mathrm{C}$ se pierden las moléculas de agua que están unidas a los iones $\mathrm{Mg}$ situados en los bordes de las capas octaédricas de los canales. El agua de coordinación y el agua enlazada a los grupos hidroxilo se pierden en el intervalo $450-610{ }^{\circ} \mathrm{C}$, dando lugar a la fase conocida como sepiolita anhidra, $\mathrm{Mg}_{8} \mathrm{Si}_{12} \mathrm{O}_{30}(\mathrm{OH})_{4}$.

Precedido de un acusado efecto endotérmico a $824{ }^{\circ} \mathrm{C}$, aparece en la zona de alta temperatura un efecto exotérmico agudo a $840{ }^{\circ} \mathrm{C}$. El primer efecto corresponde a la destrucción

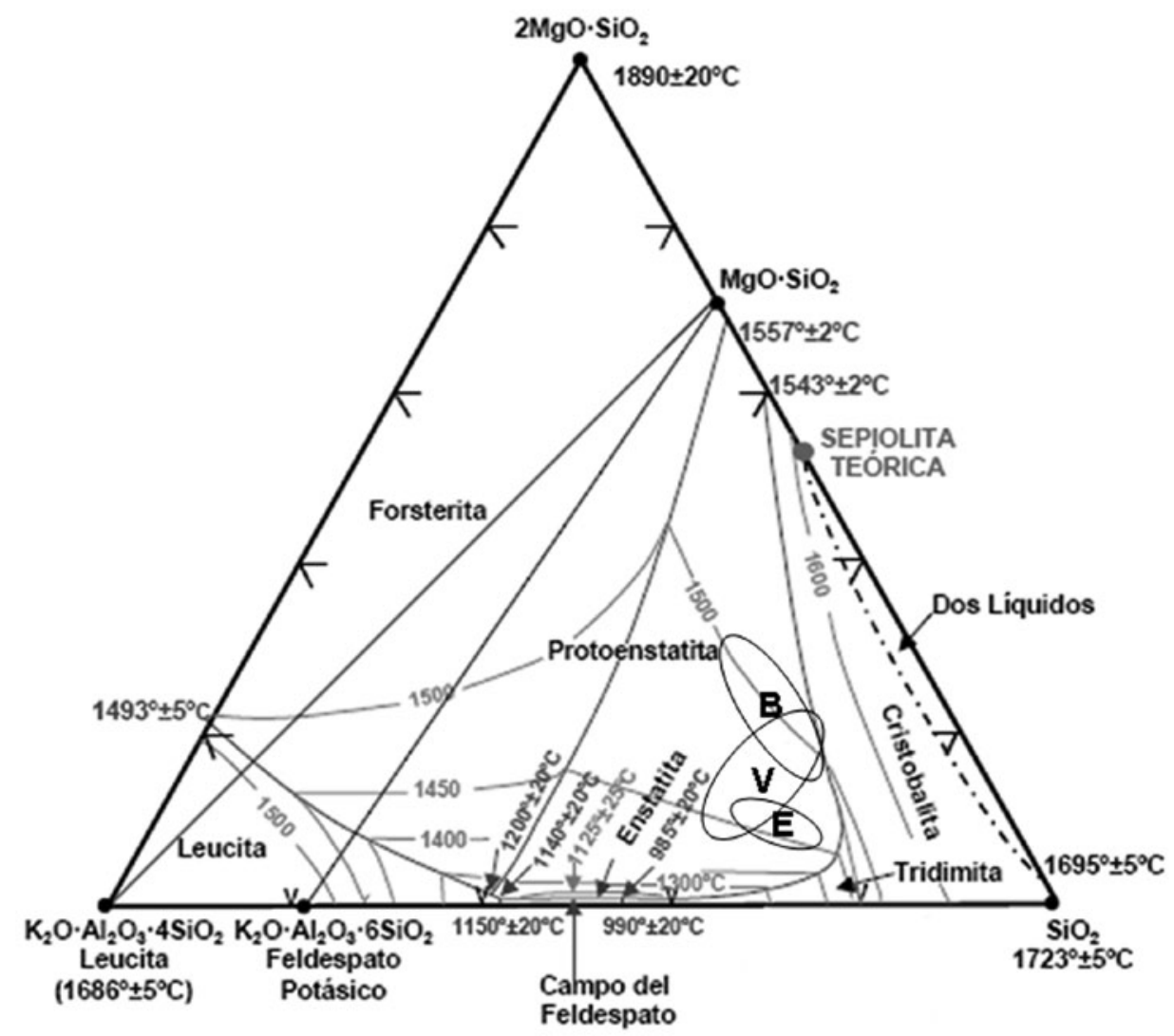

Figura 20. Sistema Sílice $\left(\mathrm{SiO}_{2}\right)$ - Forsterita $\left(\mathrm{Mg}_{2} \mathrm{SiO}_{4}\right)$ - Leucita $\left(\mathrm{K}_{2} \mathrm{O} \cdot \mathrm{Al}_{2} \mathrm{O}_{3} \cdot 4 \mathrm{SiO}_{2}\right)$. Áreas de las composiciones de vajilla $(\mathrm{V})$, baldosas (B) y escultura (E). 
de la red de la sepiolita anhidra y el segundo a la inmediata formación de enstatita (ortoenstatita), silicato magnésico $\mathrm{MgSiO}_{3}$ del grupo de los piroxenos. En este último paso se libera sílice amorfa.

La transformación $\alpha-\beta$ del cuarzo, que tiene lugar a 573 ${ }^{\circ} \mathrm{C}$, aparece en la curva derivada de la sinterización dinámica de la pasta (Figura 17) como una pequeña expansión a $580^{\circ} \mathrm{C}$. La transformación no llega a generar tensiones, al no estar la muestra densificada, y apenas repercute en el proceso dada la casi nula reactividad del cuarzo $\left(\mathrm{SiO}_{2}\right)$ a temperaturas inferiores a $1000^{\circ} \mathrm{C}$.

Por el contrario, la liberación de la sílice amorfa en la descomposición de la sepiolita marca el comienzo hacia 850 ${ }^{\circ} \mathrm{C}$ de la sinterización de la porcelana, como se observa en la curva de la derivada de la Figura 17. La alta reactividad de esta sílice amorfa con el feldespato favorece la primera formación de líquido en el sistema y la evolución de sus componentes hacia el estado de equilibrio.

En la porcelana, lo mismo que en la mayoría de los materiales cerámicos, el equilibrio no llega a alcanzarse ${ }^{51}$, pero los diagramas de equilibrio de fases sirven de guía para conocer los procesos y el alcance de las reacciones que tienen lugar en el material a alta temperatura y son una herramienta eficaz en el diseño del procesamiento cerámico ${ }^{84}$.

En la Figura 20 se representa las áreas de composición de los restos de vajilla, baldosas y escultura en el diagrama de fases leucita $\left(\mathrm{K}_{2} \mathrm{O} \cdot \mathrm{Al}_{2} \mathrm{O}_{3} \cdot 4 \mathrm{SiO}_{2}\right)$ - forsterita $\left(2 \mathrm{MgO} \cdot \mathrm{SiO}_{2}\right)$ - sílice $\left(\mathrm{SiO}_{2}\right)^{85}$, 86. Todas las composiciones (Tabla 1) se localizan en el triángulo de compatibilidad feldespato potásico $\left(\mathrm{K}_{2} \mathrm{O} \cdot \mathrm{Al}_{2} \mathrm{O}_{3} \cdot 6 \mathrm{SiO}_{2}\right)$ - enstatita $\left(\mathrm{MgO} \cdot \mathrm{SiO}_{2}\right)$ - sílice $\left(\mathrm{SiO}_{2}\right)$ en el campo primario de cristalización de la protoenstatita. La primera formación de fase líquida tiene lugar a la temperatura de $985{ }^{\circ} \mathrm{C}$, que es el punto invariante de este subsistema. A medida que la temperatura de cocción aumenta, la composición de la fase líquida se desplaza a lo largo de la línea eutéctica que separa los campos primarios de cristalización de la protoenstatita y la sílice. Debido a que esta línea monovariante corre prácticamente paralela a la arista leucita - sílice, a medida que la temperatura se eleva desde el punto invariante de $\sim 985^{\circ} \mathrm{C}$ y hasta aproximadamente $1350^{\circ} \mathrm{C}$, el contenido de líquido en el material aumenta muy ligeramente, haciéndose más viscoso al aumentar su contenido en sílice, lo que impide la deformación del material durante la cocción. Este hecho justifica el que dichos materiales tengan un amplio margen de cocción y admitan un rango de composición considerable.

El campo de cristalización de la enstatita (Figura 20) es muy pequeño y a partir de $\sim 1042{ }^{\circ} \mathrm{C}$ y hasta $1350{ }^{\circ} \mathrm{C}$, el material estará formado por protoenstatita, $\beta$-cristobalita, $\beta$-cuarzo y una fase líquida. La sílice amorfa liberada durante la descomposición de la sepiolita podría cristalizar en forma de $\beta$-cristobalita en los relictos de la arcilla (Figuras 7 y 9), análogamente a la liberada en la descomposición del metacaolín de las porcelanas triaxiales ${ }^{87}$, aunque es más probable que la cristobalita provenga mayoritariamente de la transformación del cuarzo en los bordes de grano (Figura 11).

La formación de una apreciable cantidad de $\alpha$-cristobalita ${ }^{88}$, con valores similares en las muestras de la excavación y en la porcelana preparada en el laboratorio (Figura 18) requiere que en la cocción se alcancen $1250^{\circ} \mathrm{C}$. Las microfotografías de la Figura 21 muestran la diferente densificación del material preparado en el laboratorio calcinado a 1200 y $1250{ }^{\circ} \mathrm{C}$. En el desarrollo de la microestructura de la porcelana hay que considerar otro componente, los poros ${ }^{89}$, dispersos en la matriz vítrea. La eliminación de los poros, el crecimiento de los microcristales de protoenstatita y cristobalita, la fracción de cuarzo disuelto y el desarrollo final de la microestructura dependerán directamente de la viscosidad de la fase vítrea, la temperatura alcanzada, y del tiempo de tratamiento.

En el enfriamiento las fases de la sílice revierten a las formas de baja temperatura, $\alpha$-cristobalita y $\alpha$-cuarzo, creando la estructura de pequeñas grietas circulares que se observa en la Figura 8. Aunque se suele considerar que la cristobalita rebaja la resistencia al choque térmico al originar grietas radiales desde los granos de cuarzo ${ }^{90}$, las microgrietas circulares que se observan en la porcelana de Sureda acomodarían, por el contrario, las deformaciones y absorberían las tensiones mejorando su comportamiento frente al choque térmico.

La protoenstatita cristalizada en la fase vítrea permanece metastable hasta la temperatura ambiente (Figuras 9 y 10), ya que su transformación a la fase estable de baja
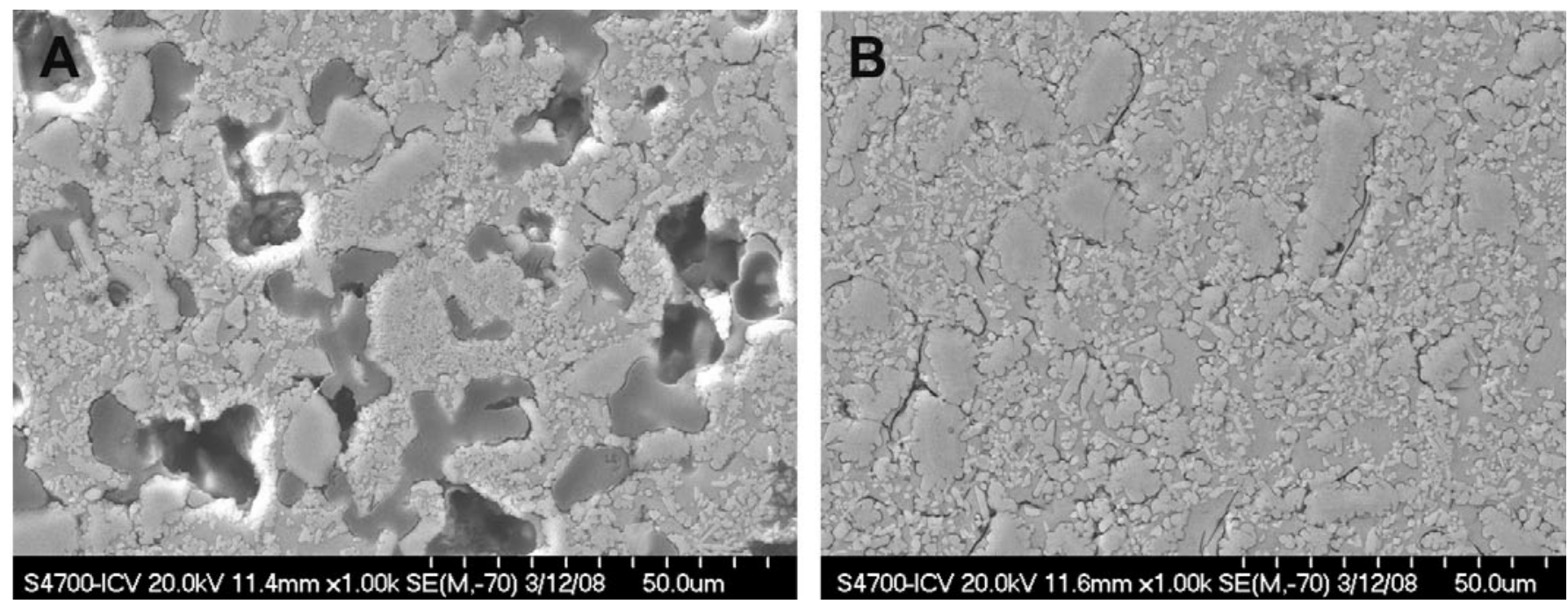

Figura 21. Microestructura de la porcelana elaborada en el laboratorio. (A) sinterizada a $1200{ }^{\circ} \mathrm{C}$, estructura altamente porosa, y (B) sinterizada a $1250^{\circ} \mathrm{C}$, estructura similar a las encontradas. 
temperatura, la enstatita, es sumamente lenta por tratarse de una transformación de tipo reconstructivo.

El análisis cuantitativo de las fases, aplicando el método Rietveld en los difractogramas de XRD de un grupo de restos de la porcelana de Sureda, mostró que ésta contenía aproximadamente un $55 \%$ de fase líquida, $8-15 \%$ de $\alpha$-cuarzo, $6-20 \%$ de $\alpha$-cristobalita y $15-20 \%$ de protoenstatita ${ }^{50}$. La concentración de $\alpha$-cuarzo, que no aparece como fase en el diagrama indica qué, y en que medida, el sistema no ha alcanzado el equilibrio ${ }^{91}$.

El diagrama justifica los resultados y permite establecer la temperatura de maduración de la pasta hacia $1250{ }^{\circ} \mathrm{C}$ y la adecuación de la fórmula de Sureda a una producción que se prolongó hasta el desmantelamiento de la Fábrica en 1808.

\section{Vidriado.}

Los datos de la Tabla 2 indican la utilización en la cubierta de un vidrio con una composición próxima a la del feldespato potásico, $\mathrm{K}_{2} \mathrm{O} \cdot \mathrm{Al}_{2} \mathrm{O}_{3} 6 \mathrm{SiO} 2$. En el Cuaderno de Notas hay un pequeño apunte "espato fusible es la cubierta de la porcelana dura. en paris ponen un poco de marne" ${ }^{\prime \prime 2}$. La adición de calcio fue práctica común también en Meissen ${ }^{93}$, pero no parece que esta fuera la fórmula utilizada al considerar el bajo contenido en $\mathrm{CaO}$ de los vidriados de la porcelana de Sureda. Es más probable que se añadiera algo de porcelana cocida según se anota en el manuscrito de Ágreda ${ }^{65}$.

\section{Barniz o cubierta \\ 24 partes Feldespato de Galapagar \\ 4 partes Porcelana cocida}

La porcelana molida que se añadía aumentaba la fusibilidad del feldespato, pudiendo justificar la presencia de $\mathrm{MgO}, 0.5-1.0 \%$, en el vidriado. La formación de la interfase, que necesariamente es un proceso de interdifusión entre el vidriado y la porcelana, también podría ser el origen del magnesio en la cubierta.

La cubierta de feldespato es una característica esencial de la porcelana dura y determina la cocción de las piezas vidriadas en dos etapas. La primera, "primer fuego", tiene lugar a baja temperatura, $1000-1100{ }^{\circ} \mathrm{C}$, en las cámaras superiores del horno (Fig 19) dando lugar al bizcocho, un material apenas sinterizado. El bizcocho se cubría con la barbotina, una suspensión de la cubierta finamente molida en agua, y se sometía a la segunda cocción. Esta segunda cocción, "gran fuego", es la que tiene lugar a alta temperatura en la cámara inferior del horno y es en la que se desarrolla la estructura de la porcelana y el vidriado. El feldespato facilita la adhesión entre la porcelana y el vidriado asegurando la continuidad y la estabilidad en la interfase que se aprecia en la figura 3.

En un sentido estricto, no existía control de la temperatura ni del tiempo. Según las notas de Sureda", "quando el horno está ardiendo ... para ver el grado del calor" se sacaban por un canal unos pedazos de la porcelana y se comprobaba el estado del vidriado. Los gases ocluidos en los poros de la porcelana migran hacia el exterior a través del vidriado y el proceso de cocción se consideraba terminado cuando el vidriado cubría totalmente la pasta sin grietas ni burbujas.

\section{Colores sobre cubierta.}

La aplicación de los colores sobre la cubierta fue la práctica más común en las porcelanas del siglo XVIII, incluidas las de Meissen $^{93}$ y Sèvres ${ }^{95}$. En la porcelana tierna la decoración se aplicaban sobre una cubierta de sílice - óxido de plomo, lo mismo que en la mayólica, y las formulaciones de los colores fueron esencialmente las mismas que describía Piccolpasso en el siglo $\mathrm{XVI}^{96}$, con excepción del púrpura de Cassius que se consiguió tras numerosos ensayos en el siglo XVII ${ }^{97}$.Sureda describe varias recetas aprendidas en Paris sobre los colores y dedica un capítulo "Colores como los preparo en Madrid" en su cuaderno ${ }^{98}$. La cocción de los colores, "tercer fuego", se aplicaba en un horno de mufla

La dificultad de la decoración en la porcelana dura era debida a la cubierta de feldespato, mucho menos fusible que la de plomo de la porcelana tierna. Así, aún adaptando la cantidad de óxido de plomo en el color, la adherencia entre las capas era baja. Este hecho es observable en el deterioro que actualmente presentan los pavimentos de porcelana de la Casita del Labrador en Aranjuez.

\section{CONCLUSIONES}

La investigación llevada a cabo sobre los restos de porcelana encontrados en la excavación del Huerto del Francés permiten concluir en este trabajo que durante la última etapa de la Real Fábrica Buen Retiro (1803-1808), bajo la dirección de Bartolomé Sureda, se fabricaron vajillas, pavimentos y esculturas con una misma pasta de porcelana dura en cuya formulación se incluía la sepiolita, una arcilla magnésica, como materia prima.

La documentación histórica recopilada ahonda sobre la situación que atravesaba la Fábrica, y el papel que tuvo Bartolomé Sureda en la creación y la fabricación de esta nueva porcelana; su formación en París; la nueva ordenación del funcionamiento de la Fábrica; la instalación de nuevos hornos y obradores; y el volumen, la tipología y las razones económicas de la producción. La revisión de los textos científicos del siglo XVIII y principios del XIX ponen de manifiesto que el desarrollo de la porcelana en Europa $y$, en concreto, la de Sureda estuvo propiciada tanto por el avance científico de la Mineralogía y la Química, como por el florecimiento de las Academias y Sociedades Científicas y la difusión del conocimiento que impulsó la Ilustración.

La caracterización físico-química de los restos de porcelana indica que el material fue formulado, como las porcelanas triaxiales, a partir de cuarzo, feldespato y arcilla; utilizando sepiolita en lugar de caolín. La interpretación conjunta de los análisis (XRF, XRD y HF-SEM) de las muestras arqueológicas, a la luz del diagrama de fases leucita - forsterita - sílice, ha permitido establecer la secuencia de reacciones que tienen lugar en la desarrollo mineralógico y microestructural de la porcelana de sepiolita y en consecuencia determinar los parámetros de la producción en la última etapa de Buen Retiro.

El análisis arqueométrico de las piezas de la excavación, que se confirma en piezas catalogadas, ha permitido establecer los elementos diferenciadores de la porcelana de Sureda frente al resto de las porcelanas de Buen Retiro y frente a otras producciones europeas de de los siglos XVIII y XIX. 
La sistematización lograda en estos datos constituye una base en la que sustentar futuros análisis no destructivos en la autenticación y puesta en valor de la obra de Buen Retiro.

\section{AGRADECIMIENTOS}

Los autores de este trabajo In Memorian de Salvador de Aza, queremos recordar la ayuda y contribución de M. Becerril, L. Céspedes, L. Cuarta, J. M. Fernández Navarro, M. A. Granados, M.S. Hernández-Crespo, A. López-Alonso, F. J. Marín, J. A. Martín-Rubí, P. Mena, P. Ortega, S. Quero, M. Regueiro, J. M. Rincón, M. Romero, M. J. Sierra, G. Yañez, de los miembros del Instituto de Cerámica y Vidrio del CSIC y de todas aquellas personas, que involuntariamente hayamos podido olvidar y que colaboraron con Salvador de Aza en los trabajos de Arqueometría sobre el Buen Retiro.

Igualmente queremos dar las gracias por su cooperación a la Dirección General del Patrimonio Histórico Artístico de la C.A. de Madrid., a la Escuela Madrileña de Cerámica de la Moncloa, al Instituto de Ciencias de la Construcción Eduardo Torroja, CSIC, al Instituto Geológico y Minero de España, al Museo Arqueológico Nacional, al Museo Municipal -Ayuntamiento de Madrid y a Patrimonio Nacional; a las empresas Tolsa y Taluell por su apoyo; y a la Dirección General de Programas y Transferencia de Conocimiento, Subdirección General de Proyectos de Investigación, por la concesión del proyecto MAT2007-62601.

\section{REFERENCIAS}

1 “Las Cerámicas del Buen Retiro". Proyecto de la Comunidad Autónoma de Madrid.CAM 06/01/04/1999.

2 "Estudio de los pavimentos para el embaldosado de la Casa del Labrador del Palacio de Aranjuez" Proyecto de la Comunidad Autónoma de Madrid. CAM 06/0112/2002

3 C. Mañueco et al. "Las porcelanas del Buen Retiro". Bol. Soc. Esp. Cerám. Vidrio, 40, 1-10 (2001).

4 “La Porcelana de los Borbones, de Capodimonte a El Buen Retiro. ¿Continuidad o innovación?" CSIC-CNR 2004-IT-0036.

5 “Conservación del Patrimonio Cerámico Nacional. Estudio de la evolución científica y tecnológica mediante técnicas analíticas avanzadas de la Porcelana en la España del Siglo XVIII". Plan Nacional de I+D+i. MAT $2007 / 62601$

6 Archivo General de Palacio, expedientes personales, 1019/24.

7 C. Mañueco. "La Real Fábrica de Porcelana del Buen Retiro a través de sus documentos (1760-1808)", en Manufactura del Buen Retiro, pp. 17-129 (p. 68, nota 233). Museo Arqueológico Nacional. Madrid. Madrid, 1999.

8 M. Pérez Villamil. Artes é industrias del Buen Retiro: La fábrica de la china, el laboratorio de piedras duras y mosaico, obradores de bronces y marfiles. p. 145. Madrid, 1904.

9 p. 68 , notas 234,235 , en referencia

10 J. Sierra e I. Tuda. “Sureda y la renovación de la cerámica española durante el primer tercio del siglo XIX, en Bartolomé Sureda (1769-1851) Arte e industria en la Ilustración tardía, pp 89-157. Museo Municipal. Madrid, 2000.

11 C. Mañueco, M.A. Granados. "Documentos, Inventarios y Catalogación de Obras". Informe del Museo Arqueológico Nacional en Memoria del Proyecto "Las Cerámicas del Buen Retiro" de la Comunidad de Madrid (06/0104/99). Madrid, 2001.

12 p. 69 , nota 243 , en referencia 7.

13 p. 68 en referencia 8.

14 p. 56 , notas $170-171$, en referencia 7.

15 C. Mañueco. "Real Fábrica de Porcelana del Buen Retiro 1760-1808", en Fábricas de la Corona, pp. 97-143 (p. 113). Alicante - Valencia, 1997.

16 C. Mañueco. "Real Fábrica Porcelana del Buen Retiro", en Reales Fábricas, pp. 111-147 (p. 126). Madrid, 1995.

17 "Notice sur une nouvelle espèce de Porcelaine", en Annales des Arts et Manufactures, t. XXIV, pp. 179-180. Ed. O’Reilly et Barbier. París, 1806.

18 p. 49 en referencia 8.
19 M. Schönfeld, "Was There a Western Inventor of Porcelain?". Technology and Culture, 39, 716-727(1998).

20 W.D. Kingery. "Medici Porcelain". Faenza, 70, 441-453 (1984).

21 A. d'Albis. "Making Soft Past in the XVIII Century". Key Engineering Materials, 132-136, 1432-1433 (1997)

22 W. D. Kingery. and D. Smith. "The development of European soft-paste (frit) porcelain". in Ancient Technology to Modern Science, Ceramics and Civilisation, vol. I, pp. 273-291.Columbus, Ohio, 1985.

23 C. M. Queiroz and S. Agathopoulos. "The discovery of European porcelain technology" in Understanding people through their pottery, pp 211-215. Trabalhos de Arqueologia, 42. Lisboa, 2005.

24 Las cartas del P. D’Entrecolles (ó Dentrecolles) se publicaron en "Lettres edifiantes et curieuses. Ecrites de Missions etrangeres, par ..." ( trasncritas en referncia 29).

25 R. A. F. de Réaumur "Des differentes maniéres dont peut faire la Porcelaine; et quelles sont les véritables maniéres de celle de la China". Memoria presentada en la Académie Royale des Sciences de Paris el 26 de abril de 1727.En Memoire de l'Academie Royal des Sciences MDCCXXVII, pp 185-203. Amsterdam, 1729.

26 R. A. F. de Réaumur. "Second mémoire sur la porcelaine ....». Memoria presentada en la Académie Royale des Sciences de Paris el 12 de noviembre de 1729.En Memoire de l'Academie Royal des Sciences MDCCXXVII, pp 370-388. Amsterdam, 1731.

27 J. H. Pott. Lithogéognosie Pyrotechnique. (Traducido al francés). París,1773.

28 M. D'Arclais de Montamy. "Mémoire sur la Porcelaine", en Traité des Coleurs ..., pp. 161-199. París, 1765.

29 M. le comte de Milly. "L'art de la porcelaine", en Descriptions des arts et métiers ..., Tome VIII, pp. 137-266. Neuchâtel, 1777.

30 "Porcelaine" en Encyclopedie ou Dictionnaire ..., tome 26, pp. 818-855. Diderot et D'Alambert. Berne - Lausanne, 1780.

31 A. Brongniart. Traité des Arts Céramiques ou des Potiers considérées dans leur Histoire, leur Practique et leur Theorie, vol. 1. París, 1844.

32 A. Brongniart. Traité des Arts Céramiques ou des Potiers considérées dans leur Histoire, leur Practique et leur Theorie, vol. 2. París, 1844.

33 G. Thalacker. “Observaciones geonósticas ... “.Anales de Historia Natural, 2 [4] 282-314 (1801).

34 L. Proust. Anales del Real Laboratorio de Química de Segovia. Segovia, 1791.

35 E. Larruga." Real Fábrica de China" en Memorias Políticas y Económicas ... , tomo IV, pp. 212-217. Madrid, 1789.

36 J. F. Riaño. "Madrid - Buen Retiro Porcelain" en The Industrial Arts in Spain, pp. 211-217. London, 1890.

37 B. Sureda Miserol. Cuaderno de Notas sobre Cerámica. 1802-1826.Edición, introducción y notas al cuidado de José Sierra Álvarez e Isabel Tuda Rodríguez. Museo Municipal de Madrid. Madrid, 2000.

38 P. Mena, F. J. Marín y G. Yañez “Intervención arqueológica en el Parque del Retiro. Estudios de documentos relativos a la Real Fábrica de Porcelanas del Buen Retiro“. Informe de la Dirección General del Patrimonio Histórico Artístico de la CAM en Memoria del Proyecto "Las Cerámicas del Buen Retiro" de la Comunidad de Madrid (06/0104/99). Madrid, 2001.

39 E. Criado, R. Martínez, F. J. Valle, P. Ortega, J. A. Martín Rubí y S. De Aza. "Estudio físico-químico, mineralógico y microestructural de diversos fragmentos de porcelanas pertenecientes a la Real Fábrica del Buen Retiro" Informe del Instituto de Cerámica y Vidrio del CSIC en Memoria del Proyecto "Las Cerámicas del Buen Retiro" de la Comunidad de Madrid (06/0104/99). Madrid, 2001.

40 C. Pascual, P. Recio, F. J. Valle, E. Criado, A. H. De Aza, R. Martínez and S. De Aza. "The last period of Buen Retiro Porcelain Factory", en Heritage,Weathering and Conservation, pp. 135-141. Taylor \& Francis. London, 2006.

41 P. 126 en referencia 7.

42 A. Zucchiatti, C. Pascual, M.D. Ynsa, L. Castelli, P. Recio, E. Criado, F. J. Valle and A. Climent-Font. "Compositional analysis of XVIII century glazed, polychrome, layered porcelain by non-destructive micro $\alpha$-PIXE". Journal of the European Ceramic Society, 28, 757-762 (2008).

43 O. Prieto, M.A. Vicente, M.A. Bañares-Muñoz. "Study of the porous solids obtained by acid treatment of a high surface area saponite". Journal of Porous Materials, 6, 335-344 (1999).

44 R.L. Frost, Z. Ding. "Controlled rate thermal analysis and differential scanning calorimetry of sepiolites and palygorskites". Thermochimica Acta, 397, 119-128 (2003).

45 C. Serna, J.L. Ahlrich, J.M. Serratosa. "Folding in sepiolite crystals". Clays and Clay Minerals, 23, 452-457 (1975).

46 H. Nagata, S. Shimoda and T. Sudo. "On dehydration of bound water of sepiolite". Clays and Clay Minerals, 22, 285-293 (1974).

47 T. Fernández. "Efecto de la deshidratacion sobre las propiedades adsorbentes de la palygorskita y sepiolita. I. Adsorcion de nitrógeno". Clay Minerals, 13, 325-335 (1978).

48 M.A. Vicente, M. Suárez, J.D. López-González, M.A. Bañarez-Muñoz. "Characterization, Surface Area, and Porosity Analyses of the Solids Obtained by Acid Leaching of a Saponite". Langmuir, 12, 566-572 (1996).

49 P. 109 en referencia 37 
50 A. H. De Aza, M. A. García de la Torre, M. A. García Aranda, F. J. Valle and S. de Aza. "Rietveld Quantitative Analysis of Buen Retiro Porcelains". J. Am. Ceram. Soc., 87, 449-54 (2004).

51 W. M. Carty and U. Senapati."Porcelain-Raw Materials, Processing, Phase Evolution, and Mechanical Behavior". J. Am. Ceram. Soc, 81, 3-20 (1998).

52 F. Singer y S. Singer. "Cerámica Industrial", vol 1-3, Enciclopedia de la Química Industrial, Tomos 9-11. Barcelona, 1971.

53 B. Sureda. "Carta fechada el 8 de noviembre de 1808", Documento transcrito por C. Mañueco, en Memoria del Proyecto "Las Cerámicas del Buen Retiro" de la Comunidad de Madrid (06/0104/99). Madrid, 2001.

54 M. S. Tite y M.Bimson. "A technological study of English porcelains". Archaeometry, 33, 3-27 (1991).

55 J. Victor Owen. "Quantification of Early Worcester Porcelain Recipes and the Distinction between Dr Wall- and Flight-period Wares". Journal of Archaeological Science, 24, 301-310(1997).

56 L. C. Freestone. "The science of early English porcelains". British Ceramic Proceedings, 60, 11-17 (1999).

57 véase, por ejemplo, P. Duhale. "Of the porcelain or China Ware", en The General History of China, vol 2, pp 309-354. 3th edition. Londres, 1741.

58 pp. 77 y 79 en referencia 37.

59 A. Brongniart. "Porcelaines dures espagnoles", en Traité des Arts Céramiques ou des Potiers considérées dans leur Histoire, leur Practique et leur Theorie, vol. 2, pp. 424-425. París, 1844.

60 A. Brongniart. "Composition générale des pates céramiques", en Traité des Arts Céramiques ou des Potiers considérées dans leur Histoire, leur Practique et leur Theorie, vol. 1, pp. 34-78. $2^{a}$ edición. París, 1854.

61 M. Gobert. "On the Magnesian Earth of Baudissero", en A Jounal of Natural Philosophy Chemistry and the Arts, vol 12, pag 325. Ed. W. Nicholson. London, 1805.

62 L. De-Mauri. Vinovo and its Porcelain. Ed. E. Piantanida Valcarenghi. Milan, 1923.

63 A. Brongniart. "Magnésite", en Traité Élémentaire de Minéralogie". Vol 1, p. 492. Paris, 1807.

64 A. Brongniart. "Notice sur la Magnésite du Bassin de Paris". p. 16. Paris, 1822.

65 C. Mañueco. “Aportaciones sobre la composición de los esmaltes, barnices y pastas de la porcelana del Buen Retiro. Nuevos datos documentales". Bol. Soc. Esp. Cerám. Vid., 39, 181-186 (2000).

66 M. Regueiro y L. Céspedes. "Los yacimientos de materias primas de la Fábrica de Porcelanas de Buen Retiro (1759-1808). Informe del Instituto Geológico y Minero de España, en Memoria del Proyecto "Las Cerámicas del Buen Retiro" de la Comunidad de Madrid (06/0104/99). Madrid, 2001.

67 A. Brongniart. "Poterie", en Dictionnaire Technologique ou Nouveau Dictionnaire Universel des Arts et Métiers, Tome Dix-septième, pp. 46-306. En Paris, 1830.

68 M. A. García del Cura, C. J. Dabrio y S. Ordoñez. "Mineral resources of the deposits of Spain", en Tertiary basins of Spain: the stratigraphic record of crustal kinematics, pp. 26-40. Ed :P. F. Friend, C. J. Dabrio. Cambridge University Press. Cambridge, 1996.

69 E. Galán. "Properties and applications of palygorskite-sepiolite clays". Clay Minerals, 31, 443-453 (1996).

70 A. C. Gurmendi. "The Mineral Industry of Spain", in Minerals Yearbook 2006, U.S. Department of the Interior. U.S. Geological Survey, November, 2008

71 M. Pozo, A.Moreno, J. Casas, J.A. Martín Rubi. “Mineralogy and geochemistry of sedimentary bentonites related to alluvial and arkosic facies (Neogene Madrid Basin, Spain)". Chem. Geol., 107, 457-461 (1993).

72 B. Casal, J. Merino, E. Ruiz-Hitzky, E. Gutierrez, A. Alvarez. "Characterization, pillaring and catalytic properties of a saponite from Vicálvaro, Madrid, Spain". Clay Minerals, 32, $39-52$ (1997).

73 J. Cuevas, R. Vigil de la Villa, S. Ramirez, S. Petit, A. Meunier, S. Leguey. "Chemistry of Mg smectites in lacustrine sediments from the Vicalvaro sepiolite deposit, Madrid neogene basin (Spain)". Clays and Clay Minerals, 51, 457-472 (2003)
74 S. Ramírez Martín, A. Garralón, J. Cuevas, J.A. Martín Rubí, J. Casas, A Álvarez, S. Leguey. “Características químicas y propiedades de superficie en secuencias -tipo de materiales esmectíticos en el yacimiento de sepiolita de Vicálvao (Madrid)". Boletín Sociedad española de Mineralogía, 19, 53-70 (1996).

75 L. B. G. de Morveau, A. Lavoisier, C. L. Berthollet y A. F. Fourcroy. Método de la Nueva Nomenclatura Química. Traduc. P. Gutierrez Bueno. Madrid, 1788

76 P. Gutierrez Bueno. "De la tierra magnesia", en Practica del Curso de Química para el Real Colegio de San Carlos, parte 1a, pp. 232-233. Madrid, 1803.

77 C. Herrgen. "Minerales para la Geografía Mineralógica de España y sus Posesiones en América", en Anales de Historia Natural, Tomo 1, p. 246. Madrid, 1799.

78 A. de Arnaud. "De la espuma de mar", en Anales de Ciencias Naturales, num ${ }^{\circ} 17$, pp. 169-171. Madrid, 1803.

79 C. Pecharromán et al. "Monodisperse and Corrosion-Resistant Metallic Nanoparticles Embedded into Sepiolite Particles for Optical and Magnetic Applications". J. Am. Ceram. Soc., 89, 3043-3049 (2006).

80 P. 15 en referencia 77.

81 D. García Fernández. "Sobre el Petun-se de la Villa de Baños, jurisdicción de Baylen" en. Anales de Historia Natural, Tomo 1, pp. 224-226. Madrid 1799.

82 M. Becerril, A. López y L. Cuadra. "Sobre los procesos de fabricación utilizados en la producción de la porcelana dura del Buen Retiro". Informe de la Escuela de Cerámica de la Moncloa, en Memoria del Proyecto "Las Cerámicas del Buen Retiro" de la Comunidad de Madrid (06/0104/99). Madrid, 2001.

83 J. F. de San Christobal y J. M. Garriga. "De las obras de Alfareria barnizadas con un barniz petreo", en Curso de Química General aplicada a las Artes, vol. 1, pp. 378-394. Paris, 1804.

84 C. B. Carter and M. G. Norton "Equilibrium Phase Diagrams", en Ceramics Materials pp. 120-138. Springer. New York, 2007.

85 J.F. Schairer. "The system $\mathrm{K}_{2} \mathrm{O}-\mathrm{MgO}-\mathrm{Al}_{2} \mathrm{O}_{3}-\mathrm{SiO}_{2}$; I. Results of quenching experiments on four joins in the tetrahedron Cordierite - Forsterite Leucite - Silica and on the join Cordierite - Mullite - Potasic Feldspar". J. Am. Ceram. Soc., 37, 501-533 (1954).

86 W.C. Luth. "The sytem $\mathrm{KAlSiO}_{4}-\mathrm{Mg}_{2} \mathrm{SiO}_{4}-\mathrm{KAlSi}_{2} \mathrm{O}_{6}$ ". J. Am. Ceram. Soc., 50, 174-176 (1967)

87 S. T. Lundin. "Microstructure of Porcelain", en Microstructure of Ceramic Materials. NBS Misc. Publ., 257, 93-106 (1964).

88 J. Requena y S. De Aza. "Sepiolita Tolsa. Estudio de los cambios mineralógicos y evolución de fases en función de la temperatura". Informe confidencial para la Compañía Tolsa. Madrid, 1985.

89 Y. Iqbal and W. E. Lee. "Fired Porcelain Microstructures Revisited". J. Am. Ceram. Soc., 82 [12] 3584-90 (1999).

90 W. D. Kingery and P. B. Vandiver. Ceramic Masterpieces: Art, Structure, Technology. New York, 1986.

91 J. Espinosa de los Monteros, S. de Aza, M.A. del Río y E.Criado. “Aplicación de los diagramas de fases ternarios a los productos de cerámica blanca". Bol. Soc. Esp. Cerám. Vidr., 12, 31-39, (1973).

92 P. 31 en referencia 37.

93 K. Domoney, A. J. Shortland and S. Kuhn. Characterization of 18th Century Meissen Porcelain using SEM-EDS. Archaeometry, on line (2011).

94 P. 29 en referencia 37.

95 P. Colomban, G. Sagon and X. Faurel. "Differentiation of antique ceramics from the Raman spectra of their coloured glazes and paintings". J. Raman Spectrosc., 32, 351-360 (2001)

96 C. Piccolpassi. I Tre Libri dell Arte del Vasajo. Edición con notas. Roma, 1857.

97 L. B. Hunt. "Gold based glass and enamels colours". Endeavour, New Series, 5, 61-67 (1981).

98 B. Sureda. "Colores como los preparo en Madrid (1803-1808)", pp. 103-109 en referencia 37. 